\title{
The Aging Brain With HIV Infection: Effects of Alcoholism or Hepatitis C Comorbidity
}

\author{
Natalie M. Zahr ${ }^{1,2 *}$ \\ ${ }^{1}$ Neuroscience Program, SRI International, Menlo Park, CA, United States, ${ }^{2}$ Department of Psychiatry and Behavioral \\ Sciences, Stanford University School of Medicine, Stanford University, Stanford, CA, United States
}

As successfully treated individuals with Human Immunodeficiency Virus (HIV)-infected age, cognitive and health challenges of normal aging ensue, burdened by HIV, treatment side effects, and high prevalence comorbidities, notably, Alcohol Use Disorders (AUD) and Hepatitis C virus (HCV) infection. In 2013, people over 55 years old accounted for $26 \%$ of the estimated number of people living with HIV ( $\sim 1.2$ million). The aging brain is increasingly vulnerable to endogenous and exogenous insult which, coupled with HIV infection and comorbid risk factors, can lead to additive or synergistic effects on cognitive and motor function. This paper reviews the literature on neuropsychological and in vivo Magnetic Resonance Imaging (MRI) evaluation of the aging HIV brain, while also considering the effects of comorbidity for AUD and HCV.

Keywords: alcohol use disorder, alcoholism, hepatitis C, magnetic resonance imaging, magnetic resonance spectroscopy, diffusion tensor imaging, neuropsychological tests

\section{OPEN ACCESS}

Edited by:

Aurel Popa-Wagner,

Department of Neurology, University

Hospital Essen, Germany

Reviewed by:

James H. Cole,

King's College London,

United Kingdom

Valerie Cardenas,

Neurobehavioral Research,

United States

*Correspondence:

Natalie M. Zahr

nzahr@stanford.edu

Received: 31 July 2017 Accepted: 20 February 2018 Published: 22 March 2018

Citation:

Zahr NM (2018) The Aging Brain With HIV Infection: Effects of Alcoholism or Hepatitis C Comorbidity.

Front. Aging Neurosci. 10:56. doi: 10.3389/fnagi.2018.00056

\section{INTRODUCTION}

The concept and benefits of combining multiple drugs for treatment of Human Immunodeficiency Virus (HIV) infection was introduced in 1996 (Gulick et al., 1997; Hammer et al., 1997). Polydrug therapies, referred to as highly active Antiretroviral Therapy (HAART) or equivalently, combination Antiretroviral Therapy (cART) were quickly incorporated into clinical practice, resulting in significantly reduced rates of hospitalizations, Acquired Immune Deficiency Syndrome (AIDS), and death (Moore and Chaisson, 1999). Because highly effective, combination regimens have since been the default in ART, and because newer one-pill options make use of the word "combination" obsolete, there has been a recent trend in referring to HIV treatments as ART instead of HAART or cART (Myhre and Sifris, 2017). Despite the effectiveness of ART in reducing HIV viral load and improving immune function, HIV infection continues to have major untoward public health and clinical consequences (Powderly, 2002).

Each year in the United States (US), 55,000-60,000 new infections are reported, with an estimated total of $\sim 1.2$ million infected individuals. In 2013 , people $\geq 50$ years old accounted for $17-26 \%$ (or up to 312,000 individuals) of the HIV population (Center for Disease Control and Prevention, 2013). Older individuals are more likely to be diagnosed later in the course of the disease; indeed, $40 \%$ of people $\geq 55$ are diagnosed with AIDS at the time of HIV diagnosis (Lindau et al., 2007; Brooks et al., 2012; Center for Disease Control and Prevention, 2015, 2016a,b). As individuals infected with HIV live longer (e.g., Thompson and Jahanshad, 2015), they are likely to accrue central nervous system (CNS) risk from factors such as substance use disorders (e.g., alcoholism), comorbid infections [e.g., hepatitis $\mathrm{C}$ virurs (HCV)], and medical conditions associated with ART treatment (Woods et al., 2004). 
The considerable comorbidity of HIV infection and alcoholism (Cook et al., 2001; Miguez et al., 2003; Samet et al., 2004, 2007; Conigliaro et al., 2006; Fuller et al., 2009; Bonacini, 2011) poses a greater public health burden than either condition alone. Individuals who drink heavily or have been diagnosed with DSM-IV alcohol abuse/dependence or DSM5 alcohol use disorder (AUD) are more likely to engage in risky sexual behaviors, delay testing for HIV, and postpone treatment (Fritz et al., 2010; Howe et al., 2011). Conversely, AUD may make it difficult for infected patients to follow the complex medication regimen prescribed to treat HIV or interfere with basic mechanisms of pharmacological treatment. HCV infects $\sim 25 \%$ of HIV-infected people in the US (Center for Disease Control and Prevention, 2011). HIV patients co-infected with $\mathrm{HCV}$, who are also likely to drink heavily (>50 g alcohol/day), have higher mortality rates than low or moderate drinkers (Bonacini, 2011).

Cross-sectional studies have been instrumental in identifying brain regions and systems affected in HIV infection, but are limited to speculation about the potential interaction of these effects with aging and variables that change with disease progression or mitigation (e.g., Ances et al., 2012). Inconsistency in findings may be, at least in part, attributable to the cross-sectional examination of a dynamic disease. Indeed, any conclusion determining whether aging interacts and exacerbates the untoward effects of HIV infection, or alternatively, whether disease progression is a greater contributor than age to decline requires longitudinal study of the relevant variables in HIVinfected groups (e.g., Holt et al., 2012; Spudich and Ances, 2012).

In longitudinal modeling of the interactions of aging and HIV, two potential trajectories are often considered: premature (additive) or accelerated (synergistic) aging. Infection may facilitate processes compromised by older age resulting in premature aging, during which changes occur earlier but in parallel to normal aging or accelerated aging, wherein changes occur at a faster rate than in normal aging (Figure 1). Results may also depend on the metric evaluated (e.g., neuropsychological performance vs. brain volumes).

In the following, the literature on brain structure and function in HIV and relevant comorbidities (i.e., AUD, HCV) is reviewed, with a focus on longitudinal studies to help clarify the independent or interactive effects of older age. Table 1 provides a list of references used herein, concentrating on manuscripts published after 2007, for HIV and each comorbid condition, also indicating cross-sectional or longitudinal studies. Table 2 summarizes key findings highlighted in this review.

\section{MEDICAL AND PSYCHIATRIC EFFECTS OF HIV AND COMORBIDITIES}

Age-related medical conditions (e.g., diabetes, hypertension, coronary artery disease, stroke, Alzheimer's disease) are not usually observed in the general population until over age 60: in HIV-infected patients, such conditions may present at middle age or sooner (Guaraldi et al., 2014). HIV-infection is also associated with frailty, the likelihood of which increases with age (Desquilbet et al., 2007). Accelerated aging in HIV may

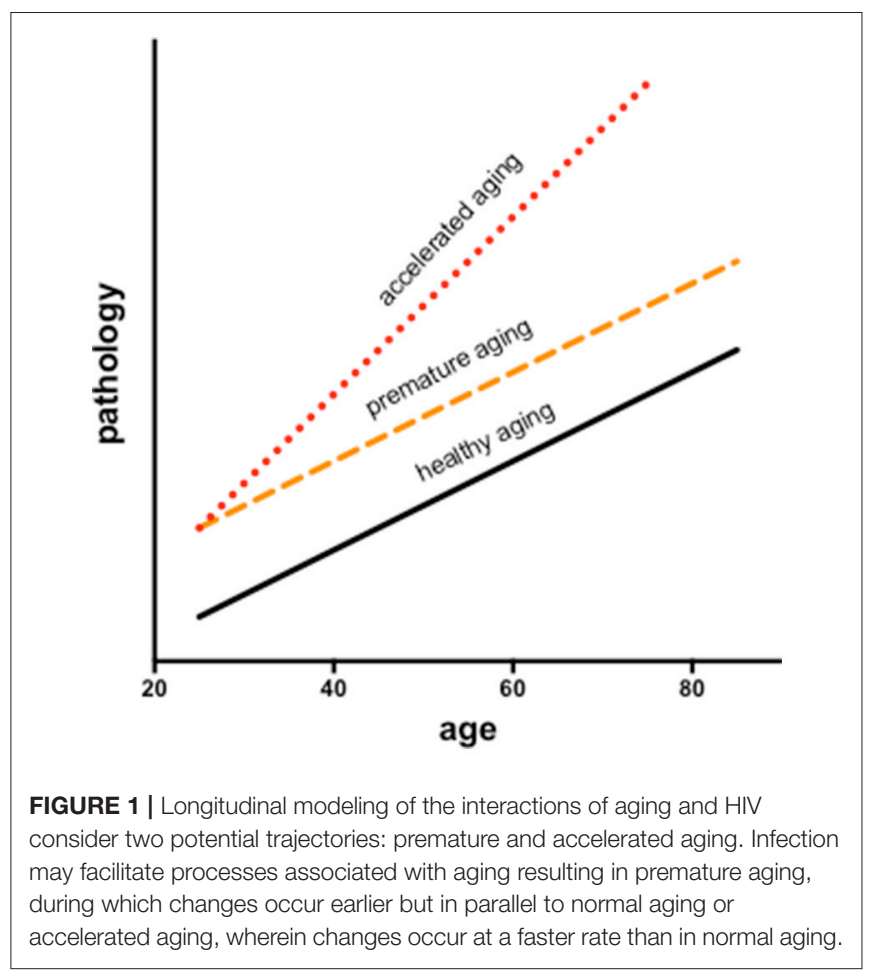

put affected individuals at increased risk for non-HIV-associated cancers (Nasi et al., 2014) and dementias (Verma and Anand, 2014; Sheppard et al., 2015).

HIV infected patients self-report feelings of apathy, lethargy, and depression (Hardy and Vance, 2009; Robertson et al., 2009; Lane et al., 2012; Zayyad and Spudich, 2015). Indeed, aging with HIV may lead to higher rates of psychiatric comorbidities (e.g., major depression, bipolar disorder, anxiety; Valcour et al., 2004; Effros et al., 2008; Leserman, 2008; Havlik et al., 2011). Medical or psychiatric comorbidities in HIV complicate access to care, interfere with self-management, and often necessitate a greater reliance on caregivers.

Because healthy aging results in global increases in immune activation and immune senescence (Schuitemaker et al., 2012), it is thought that a canonically dysregulated immune system (e.g., altered T cell production) can hasten medical or psychiatric disease (Önen and Overton, 2011), thereby contributing to premature or accelerated aging in HIV (Watkins and Treisman, 2012; Zapata and Shaw, 2014).

Medical conditions associated with AUD include liver, lung, and cardiac disease (Simet and Sisson, 2015). AUD-related liver disease has a negative effect on the progression of HIV infection (Petry, 1999; Braithwaite et al., 2007; Soboka et al., 2014; Tran et al., 2014). HIV-infected patients who drink heavily are furthermore at increased risk for cardiovascular disease (Kelso et al., 2015), certain types of cancer (McGinnis et al., 2006), and diabetes (Butt et al., 2009; Wakabayashi, 2014). AUD independently presents with depression and reduced quality of life (Sassoon et al., 2012); alcoholism in HIV likely has an additive effect on depression (Sullivan L. E. et al., 2011), stress, and anxiety (Pence et al., 2008). 


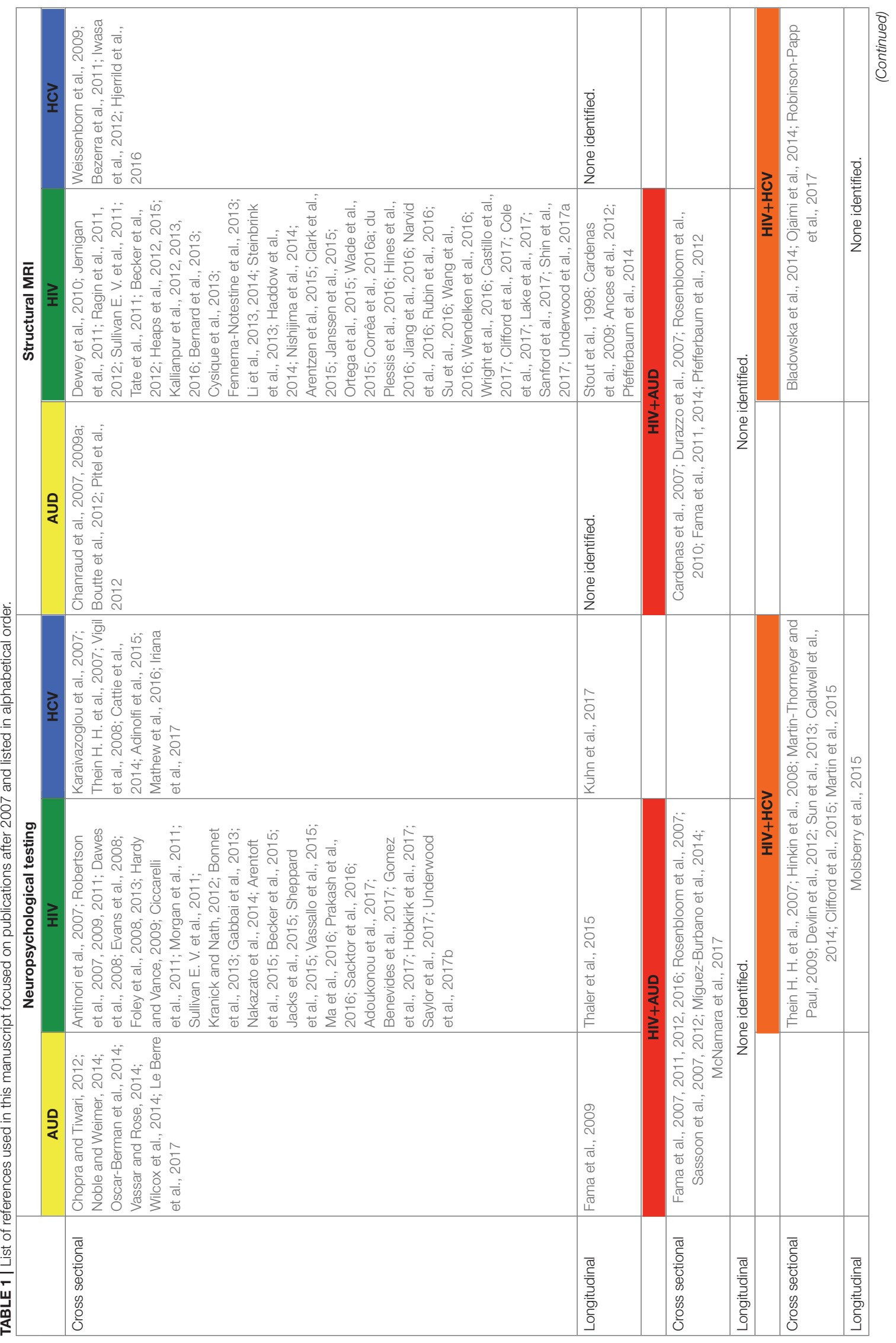




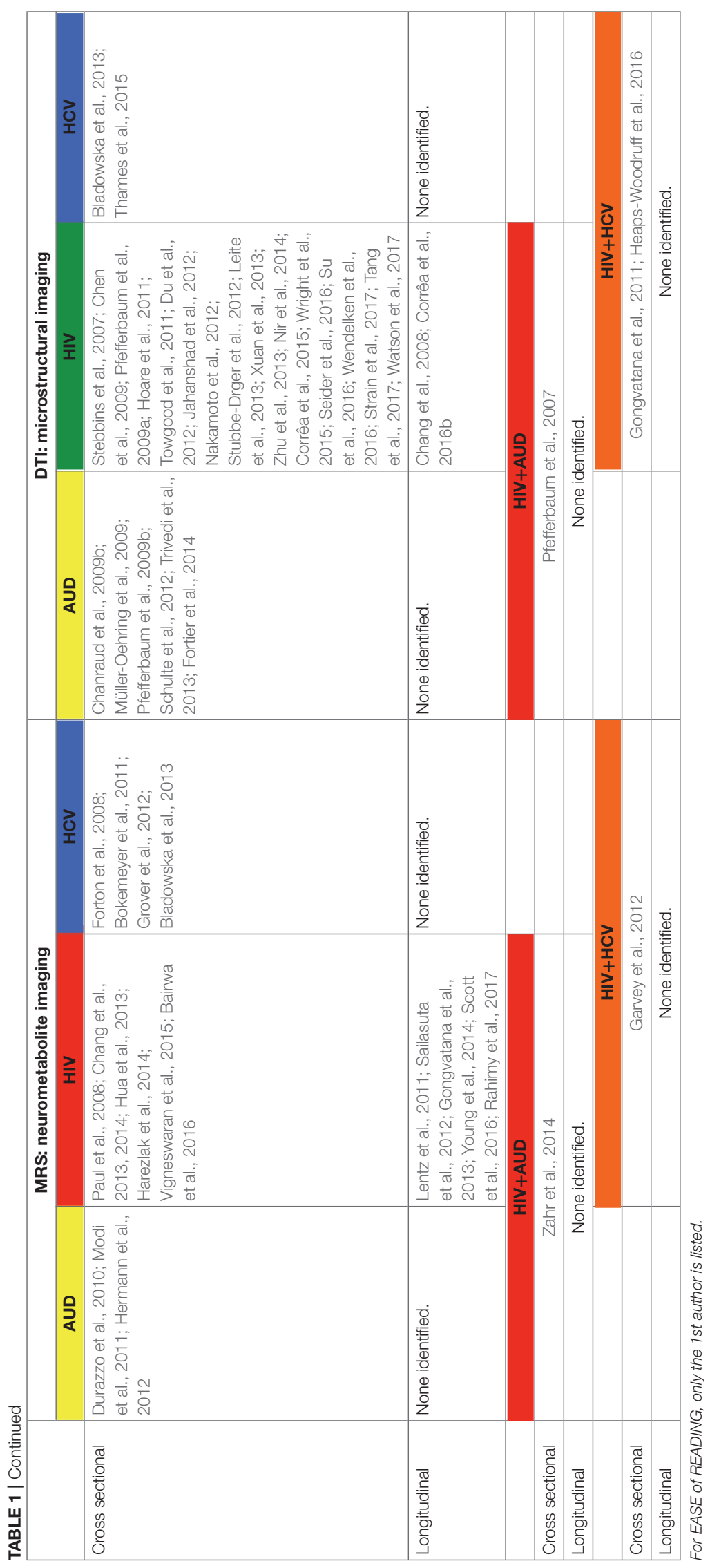


TABLE 2 | Summary of findings from manuscripts listed in Table 1.

\begin{tabular}{|c|c|c|c|c|c|}
\hline \multicolumn{3}{|c|}{ Neuropsychological testing } & \multicolumn{3}{|c|}{ Structural MRI } \\
\hline AUD & HIV & $\mathrm{HCV}$ & AUD & HIV & $\mathrm{HCV}$ \\
\hline $\begin{array}{l}\text { Visuospatial abilities } \\
\text { Emotion regulation } \\
\text { Psychomotor speed } \\
\text { Memory } \\
\text { Executive control } \\
\text { Manual dexterity } \\
\text { Gait and balance } \\
\text { Peripheral neuropathy }\end{array}$ & $\begin{array}{l}\text { Attention } \\
\text { Psychomotor speed } \\
\text { Memory } \\
\text { Executive control } \\
\text { Manual dexterity } \\
\text { Gait and balance } \\
\text { Peripheral neuropathy }\end{array}$ & $\begin{array}{l}\text { Attention } \\
\text { Psychomotor speed } \\
\text { Memory } \\
\text { Executive control } \\
\text { Manual dexterity } \\
\text { Peripheral neuropathy }\end{array}$ & $\begin{array}{l}\text { Frontal cortex } \\
\text { Thalamus } \\
\text { Hippocampus } \\
\text { Caudate } \\
\text { Putamen } \\
\text { Amygdala } \\
\text { Pons } \\
\text { Cerebellum }\end{array}$ & $\begin{array}{l}\text { Frontal cortex } \\
\text { Cingulate cortex } \\
\text { Motor cortex } \\
\text { Parietal cortex } \\
\text { Thalamus } \\
\text { Hippocampus } \\
\text { Caudate } \\
\text { Putamen } \\
\text { Pallidum }\end{array}$ & $\begin{array}{l}\text { Frontal cortex } \\
\text { Occipital cortex }\end{array}$ \\
\hline \multicolumn{2}{|c|}{ HIV+AUD } & & \multicolumn{2}{|c|}{ HIV+AUD } & \\
\hline \multicolumn{2}{|c|}{$\begin{array}{l}\text { Psychomotor speed, memory, executive control, } \\
\text { gait and balance }\end{array}$} & & \multicolumn{2}{|c|}{ Frontal and temporal cortices, thalamus } & \\
\hline \multicolumn{3}{|c|}{\begin{tabular}{|ll} 
& HIV+HCV
\end{tabular}} & & \multicolumn{2}{|c|}{$\mathrm{HIV}+\mathrm{HCV}$} \\
\hline & \multicolumn{2}{|c|}{ Memory, executive control, manual dexterity } & & \multicolumn{2}{|c|}{ Vasculitis } \\
\hline \multicolumn{3}{|c|}{ MRS: neurometabolite imaging } & \multicolumn{3}{|c|}{ DTI: microstructural imaging } \\
\hline AUD & HIV & $\mathrm{HCV}$ & AUD & HIV & $\mathrm{HCV}$ \\
\hline $\begin{array}{l}\text { Low NAA } \\
\text { Low Cho } \\
\text { Frontal/cerebellar } \\
\text { regions }\end{array}$ & $\begin{array}{l}\text { Low NAA } \\
\text { High Cho } \\
\text { High ml } \\
\text { Frontal/basal ganglia } \\
\text { regions }\end{array}$ & $\begin{array}{l}\text { Low NAA } \\
\text { High Cho } \\
\text { High } \mathrm{ml} \\
\text { Frontal/basal } \\
\text { ganglia/occipital regions }\end{array}$ & $\begin{array}{l}\text { Corpus callosum } \\
\text { (Centrum semiovale) } \\
\text { Internal capsules } \\
\text { External capsules } \\
\text { Superior cingulate } \\
\text { Longitudinal fasciculi }\end{array}$ & $\begin{array}{l}\text { Corpus callosum } \\
\text { Corona radiata } \\
\text { Internal capsules } \\
\text { External capsules } \\
\text { Superior cingulate }\end{array}$ & $\begin{array}{l}\text { Corpus callosum } \\
\text { Corona radiata } \\
\text { Longitudinal fasciculi } \\
\text { Cerebellar peduncles } \\
\text { Fronto-occipital fasciculi }\end{array}$ \\
\hline \multicolumn{2}{|c|}{ HIV+AUD } & & \multicolumn{2}{|c|}{ HIV+AUD } & \\
\hline \multicolumn{2}{|c|}{ Low NAA } & & \multicolumn{2}{|c|}{ Corpus callosum } & \\
\hline \multicolumn{3}{|c|}{ HIV+HCV } & & \multicolumn{2}{|c|}{$\mathrm{HIV}+\mathrm{HCV}$} \\
\hline & \multicolumn{2}{|c|}{ High ml } & & \multicolumn{2}{|c|}{ Corona radiata } \\
\hline
\end{tabular}

HCV liver damage progresses more rapidly in HIV and may accelerate the course and impair the management of HIV (Luetkemeyer et al., 2006; Weber et al., 2006; Chamie et al., 2007; Kim and Chung, 2009; Soriano et al., 2010). In addition, individuals seropositive for HCV have co-occurring insulin resistance beyond what might be predicted by chance (Harrison, 2008). HCV patients frequently report fatigue, lassitude, depression, and poor quality of life (Hilsabeck et al., 2003; Adinolfi et al., 2015). Emerging evidence supports an additive role of HCV and HIV on depression (Ramasubbu et al., 2012), which can negatively impact medical outcomes (Šprah et al., 2017).

\section{NEUROPSYCHOLOGICAL AND MOTOR EFFECTS OF HIV AND COMORBIDITIES}

HIV-associated neurocognitive disorder (HAND) is ideally assessed using comprehensive neuropsychological batteries and interpreted using demographically appropriate normative data (Antinori et al., 2007). Assessment of HAND allows for grading of functional impairment (Marder et al., 2003; Sacktor et al., 2016), from asymptomatic neurocognitive compromise to HIVassociated dementia (HAD) (Day et al., 1992; Maj et al., 1994; Robertson et al., 2011; Nakazato et al., 2014). The prevalence of HAD on the severe end of the spectrum has declined with ART (Gates and Cysique, 2016). Mild to moderate cognitive deficits in HIV, by contrast, remain an issue (Vivithanaporn et al., 2010; Manji et al., 2013; Underwood et al., 2017b). Despite heterogeneity (Dawes et al., 2008; Vassallo et al., 2015; Joseph et al., 2016), neuropsychological assessments of treatmentstabilized HIV patients often report compromise in domains of attention, psychomotor speed, memory, and executive control (Hinkin et al., 1999; Martin et al., 2003; Becker et al., 2015). Visuospatial abilities are relatively spared (Cysique et al., 2006), but may be sensitive to age-HIV interactions (Foley et al., 2013). Persistent cognitive impairments post-ART have been attributed to a variety of factors (e.g., immunological, genetic, psychosocial) 
(e.g., Arentoft et al., 2015; Thaler et al., 2015; Hobkirk et al., 2017), including ART, in particular efavirenz (Ciccarelli et al., 2011; Romão et al., 2011; Funes et al., 2014; Ma et al., 2016), advancing age (e.g., Morgan et al., 2011; Brew and Chan, 2014; Jacks et al., 2015; Jiang et al., 2016; Gomez et al., 2017), and comorbidity for substance use (Rosenbloom et al., 2010; Sassoon et al., 2012; Míguez-Burbano et al., 2014) or HCV infection (Devlin et al., 2012).

Motor symptoms described in the treated HIV population include slowing, clumsiness, poor balance, and loss of fine motor control (Fama et al., 2007; Robertson et al., 2007; Sullivan E. V. et al., 2011; Bernard et al., 2013; Wilson et al., 2013; Prakash et al., 2016). Peripheral neuropathy, a persisting and prevalent (15-40\%, Newton, 1995; Evans et al., 2008) HIV-associated disturbance in the post-ART era (Geraci and Simpson, 2001; Robertson et al., 2011; Kranick and Nath, 2012; Gabbai et al., 2013), is also associated with older age (Saylor et al., 2017) and ART (Dragovic and Jevtovic, 2003; Venhoff et al., 2010; Birbal et al., 2016; Weldegebreal et al., 2016; Adoukonou et al., 2017; Benevides et al., 2017) and likely contributes to impaired motor control.

Indeed, toxicity of ART goes beyond originally reported side effects of medications. An unexpected relationship between high current CD4 and deterioration of clinical status is an active area of investigation (e.g., Jernigan et al., 2011; Nasi et al., 2017) and a growing concern for the aging HIV population (Manji et al., 2013; Zaffiri et al., 2013). This condition, referred to immune reconstitution inflammatory syndrome (IRIS), applies to HIV patients who experience worsening symptoms as a result of anti-retroviral therapy mediated immune restoration (Venkataramana et al., 2006; Johnson and Nath, 2010). The effects of IRIS on brain structure may not be visible with conventional MRI (Narvid et al., 2016), but may be detectable with quantitative diffusion tensor imaging (DTI) (Zhu et al., 2013), which focuses on the integrity of white matter microstructure.

To account for variability seen in neuropsychological performance in cross-sectional studies (Schretlen et al., 2003), it has been posited that an increase over time (6-month interval) in intra-individual variability (or dispersion) in neurocognitive performance contributes to poorer antiretroviral medication adherence, which in turn can lead to additional neurocognitive impairments, precipitating a deteriorating cycle (Thaler et al., 2015). The Multicenter AIDS Cohort Study (MACS) enrolled a total of 6972 men from sites in Baltimore, Washington, Chicago, Los Angeles, and Pittsburgh at three separate time points: in 1984-1985, 1987-1991, and 2001-2003. Neuropsychological evaluation included measures from multiple domains. A datadriven Mixed Membership Trajectory Model technique was used to investigate potential trajectories of cognitive impairment. The findings suggest three distinct trajectories: "normal aging" was defined as a low probability of mild impairment until age 60; "premature aging" was defined as mild impairment starting at age 45-50 (i.e., "premature aging" relative to "normal aging" was offset to the left by $25+$ years); "unhealthy aging" was defined as mild impairment at ages 20-39. Clinically defined AIDS, HCVinfection, depression, and race affected an individual's trajectory classification (Molsberry et al., 2015). Our work comports with the results of the MAPS study showing that cognitive performance slope differences between control and HIV groups can be modeled as premature aging, in that differences between the patients and the controls occur without interactions with aging (Pfefferbaum et al., 2014).

Studies focused on neuropsychological performance in AUD show impairments in memory, psychomotor speed, and executive functioning: problems in visuospatial and emotional regulation domains appear to be unique to AUD (Chanraud et al., 2007; Fama et al., 2009; Oscar-Berman et al., 2014; Wilcox et al., 2014; Le Berre et al., 2017). Motor effects of AUD include compromise of upper limb motor abilities, and gait and balance (Sullivan et al., 2000b,c, 2002; Vassar and Rose, 2014). Peripheral neuropathy reported in AUD has been related to nutritional deficiencies (Chopra and Tiwari, 2012; Noble and Weimer, 2014).

Substance abuse can independently contribute to neuropsychological impairments in HIV (e.g., Gomez et al., 2017). In a recent study, $52 \%$ of HIV positive patients showed cognitive deficits, often related to high alcohol consumption (McNamara et al., 2017). In studies aimed at discerning the independent effects of HIV and AUD (e.g., Fama et al., 2012), impairments in planning and free recall of visuospatial material marked AUD, whereas impairments in psychomotor speed, sequencing, narrative free recall, and pattern recognition marked HIV. Our work demonstrates that tests of executive function, episodic memory, and processing efficiency (expressed as ageand education-corrected composite Z-scores) show a graded effect, with HIV+AUD performing worse than controls on executive function and episodic memory and worse than AUD alone or HIV alone on episodic memory (Fama et al., 2016): in HIV+AUD, age was a unique predictor of poor episodic memory (Figure 2). Our work comports with the literature that comorbidity for HIV+AUD results in compounding effects (Rothlind et al., 2005; Fama et al., 2014) on declarative memory (Fama et al., 2009, 2016), remote memory (Fama et al., 2011), selective attention and conflict processing (Schulte et al., 2005), psychomotor speed (Sassoon et al., 2007), gait and balance (Fama et al., 2007), and quality of life (Rosenbloom et al., 2007).

$\mathrm{HCV}$-infected individuals experience cognitive decline even in the absence of cirrhosis-associated hepatic encephalopathy or other indices of liver damage (Karaivazoglou et al., 2007). Some groups have argued that cognitive deficits in HCV are due to interferon treatment (Asnis and Migdal, 2005; Capuron et al., 2005; Reichenberg et al., 2005), but cognitive deficits persist despite successful antiviral (interferon) therapy (Thein H. H. et al., 2007; Weissenborn et al., 2009; Cattie et al., 2014; Kuhn et al., 2017). Although the literature is heterogeneous and characterized by cross-sectional rather than longitudinal assessments of relatively small and select cohorts, neurocognitive deficits reported in $\mathrm{HCV}$ include compromised attention, memory, and psychomotor speed (Forton et al., 2002; Hilsabeck et al., 2002; Capuron et al., 2005; Iriana et al., 2017) with fewer reports of deficits in executive functioning (Córdoba et al., 2003; Weissenborn et al., 2004), fine-motor coordination (Vigil et al., 2008), and presence of peripheral neuropathy (Adinolfi et al., 2015; Mathew et al., 2016). 


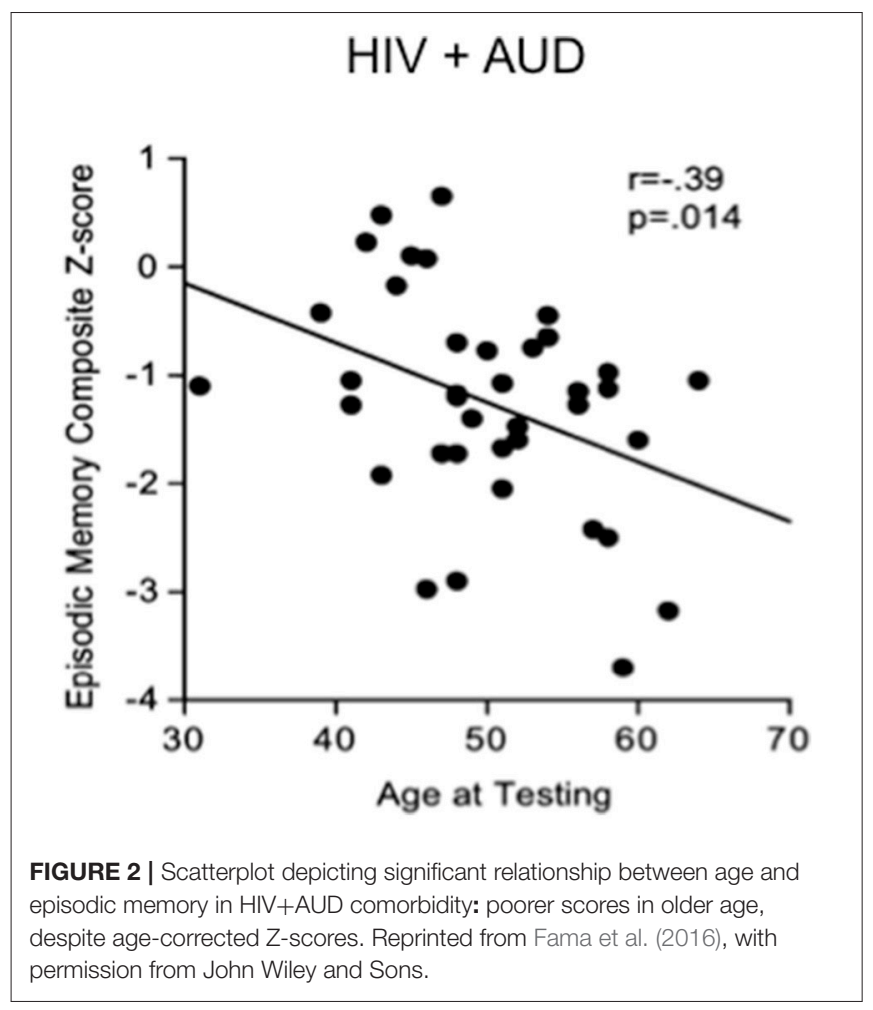

Studies reporting on the combined effects of HIV and HCV on neuropsychological performance suggest that the two viruses result in similar neurocognitive consequences (cf., Parsons et al., 2006; Thein H. et al., 2007; Martin-Thormeyer and Paul, 2009; Martin et al., 2015; Molsberry et al., 2015) with comorbidity associated with greater neurocognitive impairment than in either infection alone (Hilsabeck et al., 2003; von Giesen et al., 2004; Cherner et al., 2005; Letendre et al., 2005; Richardson et al., 2005; Sun et al., 2013; Caldwell et al., 2014; but see: Perry et al., 2005; Soogoor et al., 2006; Clifford et al., 2015), particularly on measures of memory (Hilsabeck et al., 2005; Hinkin et al., 2008), executive functioning (Ryan et al., 2004), and motor dexterity (Cherner et al., 2005).

In summary, available evidence suggests that neurocognitive performance in ART-treated HIV individuals shows premature aging. HIV, AUD, and $\mathrm{HCV}$ can independently impair neuropsychological functioning and appear to have additive effects on some domains of cognition, which in practice can have significant effects on key outcomes such as employment status (van Gorp et al., 1999; Heaton et al., 2004), medication adherence (Hinkin et al., 2004), and driving safety (Marcotte et al., 2006).

\section{IN VIVO NEUROIMAGING OF HIV AND COMORBIDITIES}

\section{Macrostructural Magnetic Resonance Imaging (MRI)}

In the ART era, clinical MRI scanning reveals relatively few gross intracranial abnormalities in HIV, particularly when neurological signs are absent (Nishijima et al., 2014). Although severe brain atrophy is uncommon in HIV stabilized by treatment, brain volume deficits can be detected with quantitative methods in select regions of the cortex, basal ganglia, and cerebellum (Aylward et al., 1993; Di Sclafani et al., 1997; Stout et al., 1998; Tagliati et al., 1998; Ragin et al., 2012; Kallianpur et al., 2013; Underwood et al., 2017a). Cortical areas with gray matter volume deficits in HIV with viral suppression, relative to healthy controls, include frontal, cingulate, sensorimotor, and parietal regions (Heaps et al., 2012; Li et al., 2014; Pfefferbaum et al., 2014; Clark et al., 2015; Janssen et al., 2015; Wang et al., 2016). Those without complete viral suppression exhibit greater volume deficits than virally-suppressed individuals (Cardenas et al., 2009; Kallianpur et al., 2013; Hines et al., 2016). The imaging literature typically reports the effects of HIV on gray matter volume [see the following for exceptions] (Corrêa et al., 2016a; du Plessis et al., 2016; Castillo et al., 2017). In studies that assessed cortical thickness rather than cortical volume, HIV effects can be evident in areas such as the insula and temporal cortices (Kallianpur et al., 2012; Sanford et al., 2017).

Subcortical regions with significantly smaller volumes, particularly in older HIV subjects relative to healthy controls, include thalamus, hippocampus, caudate, putamen, and pallidum (Dewey et al., 2010; Li et al., 2013; Wade et al., 2015; du Plessis et al., 2016; Wright et al., 2016; Sanford et al., 2017). Brain tissue abnormalities have been reported to correlate with nadir CD4 cell counts (Thompson et al., 2005; Jernigan et al., 2011; Kallianpur et al., 2012; Hua et al., 2013). However, HIV individuals with an active life style (energy use above resting expenditure) were found to have a larger putamen (Ortega et al., 2015), and longitudinal study reveals that increasing CD4 counts (notwithstanding IRIS) are associated with increases in subcortical gray matter volumes (Fennema-Notestine et al., 2013) and slower tissue volume declines (Pfefferbaum et al., 2014).

As described for compromised neuropsychological performance in HIV, brain volume deficits in the ART era may be associated with more traditional risk factors (e.g., age, education, diabetes) than with HIV-related variables (Bonnet et al., 2013; Lake et al., 2017; but see Ragin et al., 2011; Kallianpur et al., 2016). Although HIV and aging appear to contribute independently to heighten brain structural vulnerability (Ances et al., 2012), HIV may accelerate brain aging (Cysique et al., 2013; Cole et al., 2017). Consequently, despite persistent control of plasma viremia, older HIV infected patients demonstrate more rapid progressive brain compromise when compared to healthy aging (Clifford et al., 2017).

The few published longitudinal volumetric MRI studies have been conducted over relatively brief intervals, typically $1-2$ years. An initial study found faster rate of cortical volume decline in mild (CDC stage A) and severe (CDC stage C) stages of $\mathrm{HIV}$ infection relative to changes observed in infection-free controls and faster rates of white matter volume decline in the HIV-infected subgroup with stage C than stage A severity level. Further, decline in caudate nucleus volume and increase in ventricular volume were greater in the HIV-infected group that progressed from a less severe to a more severe CDC stage across MRI sessions, and these changes in brain volumes 
correlated with decline in CD4 cell count (Stout et al., 1998). A 2-year longitudinal study indicated widespread white matter volume loss and posterior gray matter loss (parietal, occipital, and cerebellar) in virally-suppressed HIV individuals, depending on analysis approach; those without complete viral suppression exhibited accelerated volume loss in gray and white matter compared with declines measured in controls (Cardenas et al., 2009). Examination of HIV infected individuals before and about 6 months after starting ART revealed improvement in neuropsychological test performance but no appreciable change in regional brain volumes (Ances et al., 2012). In this relatively small study, older age and HIV infection were independently related to smaller volumes of the caudate, with evidence for premature aging of the caudate in HIV-infected participants, while volumes of the amygdala and corpus callosum were sensitive to HIV but not aging.

We evaluated brains of $51 \mathrm{HIV}$ and 65 controls from 351 longitudinal MRI scans and concurrent neuropsychological evaluation collected 2 or more times over 6 months to 8 years (Pfefferbaum et al., 2014). Although HIV individuals were in good general health and free of clinically detectable dementia, significant volume effects, where HIV-infected participants had greater volumes in CSF regions and smaller volumes in tissue regions than controls, were found in the Sylvian fissures, cingulum, insula, thalamus, and hippocampus. Significant slope effects, where the HIV-infected group showed greater change per year over the years of observation than the control group, were detected in the lateral ventricles, insula, and hippocampus. Greater acceleration in slope with advancing age in the HIVinfected individuals was found for frontal, temporal, and parietal cortices and thalamus (Figure 3). In this study, the most consistent and robust predictors of brain volume trajectories were CD4 count and duration of HIV infection (Pfefferbaum et al., 2014).

Effects of HIV and comorbid substance abuse on brain structure can depend on the substance and quantity consumed [e.g.,] (Durazzo et al., 2007; Thames et al., 2017). In AUD, volume deficits are evident in brain regions including frontal cortex (Pfefferbaum et al., 1997; Cardenas et al., 2005, 2007), cerebellum (i.e., hemispheres; Sullivan et al., 2000a,c; De Bellis et al., 2005; Chanraud et al., 2007, 2009a; Boutte et al., 2012), pons (Pfefferbaum et al., 2002a; Sullivan, 2003; Chanraud et al., 2009b), mammillary bodies (Shear et al., 1996; Sullivan et al., 1999), hippocampus, thalamus (Sullivan, 2003; De Bellis et al., 2005; Chanraud et al., 2007; Pitel et al., 2012; van Holst et al., 2012), caudate (Boutte et al., 2012), putamen (Jernigan et al., 1991), amygdala (Fein et al., 2006), and nucleus accumbens (Sullivan et al., 2005). Those with both HIV infection and alcoholism show ventricular enlargement greater than in either condition alone (Rosenbloom et al., 2010). Quantitative analysis of MRI brain structural data from cross-sectional study of 4-groups (controls, AUD, HIV, HIV+AUD) revealed regional volume deficits in all 3 patient groups: HIV alone had relatively few deficits, except in thalamus (Pfefferbaum et al., 2012), as has recently been replicated (Janssen et al., 2015); HIV+AUD showed moderate to severe abnormalities affecting multiple brain regions (e.g., frontal and temporal cortices, thalamus, corpus callosum, Sylvian fissure, 3rd ventricle); and HIV+AUD with an AIDS diagnosis had the most serious untoward effects on brain structure (Pfefferbaum et al., 2012).

In non-cirrhotic $\mathrm{HCV}$ patients relative to controls, a recent study suggests that cortical thickness is reduced in frontal and occipital cortices (Hjerrild et al., 2016; also see Iwasa et al., 2012). $\mathrm{HIV}+\mathrm{HCV}$ co-infection has been associated with increased incidence of neurovascular disease (Jernigan et al., 2011; Ojaimi et al., 2014; but see Ramos-Casals et al., 2007) and compromised brain perfusion (Bladowska et al., 2014), but the effects of HIV and HCV co-infection on brain macrostructural integrity is an area for further investigation. In summary, structural imaging suggests that HIV infection may lead to accelerated aging of the brain, which is compounded by AUD comorbidity, particularly in subcortical regions such as the thalamus. Additional work is required to determine whether non-cirrhotic $\mathrm{HCV}$ is associated with regional brain volume deficits and whether $\mathrm{HIV}+\mathrm{HCV}$ coinfection has additive effects on reducing regional brain volumes.

\section{White Matter Hyperintensities}

White matter damage can be measured by examining white matter hyperintensities (WMH) on fluid attenuated inversion recovery (FLAIR) images from MRI. WMH may reflect vascular or inflammatory brain changes (Maniega et al., 2015; Shoamanesh et al., 2015). The prevalence of cerebrovascular events in HIV remains higher, in relatively younger patients, despite treatment, than in the general population (Haddow et al., 2014; Arentzen et al., 2015). The frequency of cerebrovascular disease increases with age (Kendall et al., 2014) and HIV individuals with cerebrovascular disease are more likely to have cognitive deficits (Foley et al., 2008; Nakamoto et al., 2012).

WMH are a frequent finding on brain MRI of elderly subjects (over aged 60) and associated with hypertension (e.g., Rostrup et al., 2012; Peng et al., 2014). A number of studies report a greater prevalence of WMH in HIV relative to healthy controls (Foley et al., 2008; Su et al., 2016), specifically affecting frontal lobes (McMurtray et al., 2008). While one study reports that with older age, patients with HIV have a greater number of WMH relative to age-matched healthy controls related to a history of AIDS, current CD4, and active HCV infection (Seider et al., 2016), another found a similar number of WMH volumes in HIV and controls (Watson et al., 2017), explained by hypertension (Su et al., 2016; Watson et al., 2017).

There is little evidence that alcohol consumption increases WMH load (e.g., Anstey et al., 2006). In non-cirrhotic HCV patients relative to controls, imaging provides evidence for an increased incidence of $\mathrm{WMH}$ representing cerebral vasculitis (Heckmann et al., 1999; Casato et al., 2005; Bezerra et al., 2011). Indeed, in $\mathrm{HIV}$, the presence of $\mathrm{HCV}$ was the strongest predictor of WMH (Robinson-Papp et al., 2017).

\section{Structure/Function Relationships}

A primary goal of evaluating structure/function relationships in HIV is to advance understanding of the neural substrates of HIV-associated motor and cognitive compromise. Significant, but non-specific correlations have been reported between the severity of global brain atrophy and general cognitive 

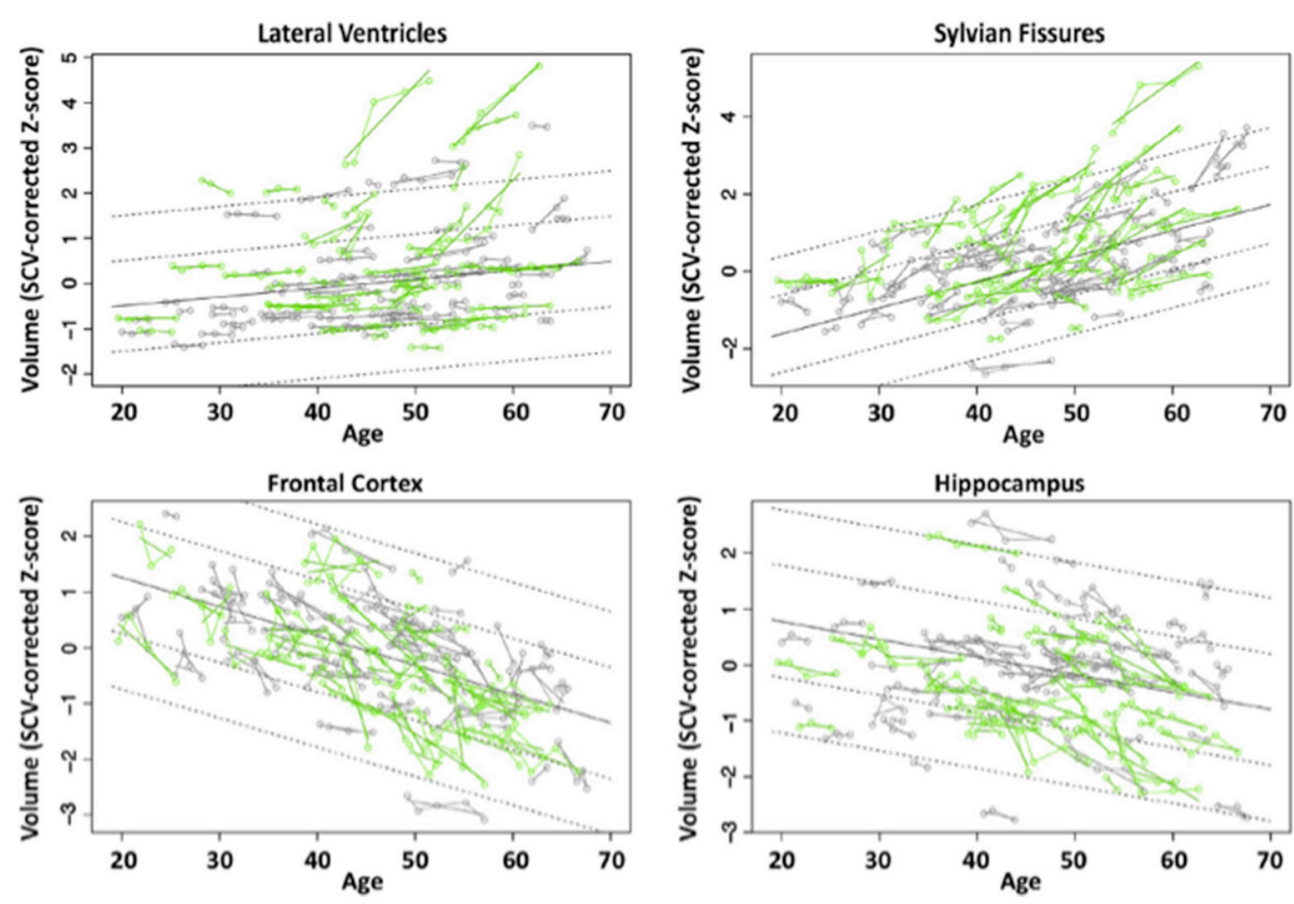

FIGURE 3 | Plots of individual supratentorial cranial volume (SCV)-corrected Z-scores by age for each control (gray) and each HIV-infected participant (green) for the lateral ventricles, Sylvian fissures, frontal cortex, and hippocampus. Each participant's values are connected over time and the age-centered slope of each participant is overlaid on his or her longitudinal data points. The long solid black regression line is the expected volume by age regression based on the controls; dotted lines are \pm 1 and 2 standard deviations. Reprinted from Pfefferbaum et al. (2014) with permission from Elsevier.

impairment in HIV (Becker et al., 2012; Steinbrink et al., 2013; but see Heaps et al., 2015). By contrast, cortical thinning of the retrosplenial cortex has been proposed as a selective contributor to general cognitive impairment in HIV (Shin et al., 2017). A number of studies report deficits in regional brain volumes associated with poor cognitive performance in HIV: the caudate with psychomotor performance (Kieburtz et al., 1996; Paul et al., 2002; Kallianpur et al., 2016); the anterior cingulate with emotion processing (Clark et al., 2015); the prefrontal cortex with verbal learning and memory (Rubin et al., 2016). The assortment of brain regions implicated likely reflects heterogeneity in disease course. Indeed, postART, global, cortical-driven pathogenesis rather than subcortical dysfunction is a more likely contributor the varying HIV clinical manifestations (Foley et al., 2008). Cognitive heterogeneity post-ART thus requires further evaluation of select brain structure/function relationships, particularly in stably-treated, aging HIV cohorts, with comorbid risk factors.

In HIV-infected alcoholics, smaller thalamic volumes were associated with poorer performance on tests of explicit (immediate and delayed) and implicit (visuomotor procedural) memory (Fama et al., 2014), again indicating the thalamus as a structure that is particularly susceptible to HIV and the compounding effects of AUD. The potential for segmentation of thalamic subregions (Behrens et al., 2003; Deoni et al., 2007; Zhang et al., 2010; Deistung et al., 2013; Kim et al., 2013; Barron et al., 2014) holds promise for a more refined understanding of brain structure/function relationships and affected neural circuitry (Fama et al., 2016) in HIV.

\section{Magnetic Resonance Spectroscopy (MRS)}

MRS is a modality used to quantify brain metabolites, typically $\mathrm{N}$-acetyl aspartate (NAA), choline-containing compounds (Cho), and total creatine (tCr). NAA is an indicator of neuronal integrity, with decreases suggesting neuronal dysfunction (e.g., Zahr et al., 2010, 2013). The signal from Cho, including contributions from free choline, glycerophosphorylcholine, and phosphorylcholine (Miller, 1991), is a marker for cell membrane synthesis and turnover. The signal from tCr, with contributions from creatine and phosphocreatine, represents the high-energy biochemical reserves of neurons and glia (Inglese et al., 2003). Less frequently reported, as their quantification is more challenging, are levels of myo-Inositol (mI) and glutamate (Glu). Because $\mathrm{mI}$, an osmolyte, is primarily present in glial cells (Brand et al., 1993), it is considered a glial marker. Glu is a ubiquitous molecule used in cellular metabolism and is the principal excitatory neurotransmitter (Thangnipon et al., 1983; Fonnum, 1984).

MRS studies of HIV patients commonly report that neuronal injury (dysfunction or loss) is associated with low levels of NAA and changes (both increases and decreases) in Glu levels (often quantified from the combined resonance of glutamate + glutamine and referred to as Glx) in regions including frontal cortex and basal ganglia (López-Villegas et al., 1997; Chang et al., 
1999, 2013; Paul et al., 2008; Hua et al., 2013; Harezlak et al., 2014; Bairwa et al., 2016); longitudinal: (Lentz et al., 2011; Sailasuta et al., 2012; Gongvatana et al., 2013; Young et al., 2014; Scott et al., 2016; Rahimy et al., 2017). Similar findings of abnormally low NAA (McAndrews et al., 2005) are also reported in HCV in regions such as the occipital cortex (Weissenborn et al., 2004); but see (Bokemeyer et al., 2011).

During acute/early infection and at two follow-up time points (2 and 6 months), greater numbers of activated (CD16+) monocytes were associated with lower NAA and higher Cho levels in frontal cortex (Lentz et al., 2011). Similarly, above control levels of Cho were identified in basal ganglia in acute $\mathrm{HIV}$; these resolved to control levels at 6 month following initiation of ART (Sailasuta et al., 2012). Similar findings (longitudinal increases in Cho) were reported in frontal white matter and parietal gray matter prior to ART initiation, with resolution following ART (Young et al., 2014). By contrast, a study in chronic HIV with longer intervals between MRS showed that despite stable ART and virological suppression, and in both asymptomatic and cognitively impaired subgroups, HIV-infected subjects showed significant annual decreases in brain metabolites (including NAA, Cho, tCr, and Glx) in midfrontal cortex, frontal white matter, and basal ganglia (Gongvatana et al., 2013).

Most MRS studies show lower levels of NAA in recently sober alcoholics relative to healthy subjects in several brain regions including frontal areas (Fein et al., 1994; Jagannathan et al., 1996; Seitz et al., 1999; Bendszus et al., 2001; Schweinsburg et al., 2003; Durazzo et al., 2004, 2010; Meyerhoff et al., 2004) and cerebellum (Jagannathan et al., 1996; Seitz et al., 1999; Bendszus et al., 2001; Parks et al., 2002; Durazzo et al., 2010). Neuronal compromise (reduced NAA) appears to be compounded in HIV+AUD (Pfefferbaum et al., 2005). Below control levels of Cho in AUD patients shortly following detoxification are also reported in frontal (Fein et al., 1994; Durazzo et al., 2004; Ende et al., 2005) and cerebellar (Seitz et al., 1999; Bendszus et al., 2001; Parks et al., 2002; Ende et al., 2005; Pfefferbaum et al., 2005; but see Modi et al., 2011; Hermann et al., 2012) regions.

Neuroinflammation in either HIV or $\mathrm{HCV}$ has been associated with elevated levels of $\mathrm{mI}$, Cho, and $\mathrm{tCr}$ in frontal and basal ganglia regions (Chong et al., 1993; English et al., 1997; Forton et al., 2001, 2002, 2008; Chang et al., 2002, 2013, 2014; Fuller et al., 2004; Weissenborn et al., 2004; McAndrews et al., 2005; Grover et al., 2012; Bladowska et al., 2013). MRS studies of HIV + HCV suggest that co-infection might be associated with higher $\mathrm{mI}$ (Garvey et al., 2012) and less variability and more reliability in reported metabolite changes (Vigneswaran et al., 2015).

In a previously published work, we challenged the specificity of Cho and $\mathrm{mI}$ as markers of neuroinflammation. Significant group effects were evident for striatal Cho and striatal $\mathrm{mI}$, higher in HIV+AUD than in controls (Figure 4). Correlations evaluated in HIV groups only (i.e., HIV, HIV+AUD) demonstrated that having $\mathrm{HCV}$ or an AIDS-defining event was associated with higher Cho; lower Cho levels, however, were associated with low thiamine levels and with ART. Higher levels of $\mathrm{mI}$ were related to greater lifetime alcohol consumed, whereas ART was associated with lower $\mathrm{mI}$ levels (Zahr et al., 2014). These results demonstrate that competing mechanisms can influence Cho and $\mathrm{mI}$ levels, and that elevations in these metabolites cannot necessarily be interpreted as reflecting a single underlying mechanism such as neuroinflammation.

\section{Microstructural Diffusion Tensor Imaging (DTI)}

Examination of brain microstructural integrity using DTI has detected subtle HIV-related differences from controls [e.g., low fractional anisotropy (FA) and high mean diffusivity (MD)] in markers of myelin (radial or transverse diffusivity) and axonal (axial or longitudinal) integrity, even in normal-appearing white matter, notably in corpus callosum and frontal lobe white matter (e.g., Pfefferbaum et al., 2007, 2009a; Chen et al., 2009; Hoare et al., 2011; Towgood et al., 2011; Du et al., 2012). Variable results from DTI studies may be due, at least in part, to timing of evaluation relative to treatment (i.e., treatment naïve, currently un-medicated, chronically medicated, or older HIV infected individuals). For example, in early, treatment naïve HIV infection, white matter impairment (Tang et al., 2017) correlated with days since infection (Wright et al., 2015). In those on ART, a number of fiber tracts, including those of the corpus callosum and corona radiate are often reported as compromised (Leite et al., 2013; Xuan et al., 2013; Su et al., 2016; Wang et al., 2016). Effects on DTI metrics may also depend on presence of neurological complications (Corrêa et al., 2015), with symptomatic individuals showing effects extending to frontal areas (Zhu et al., 2013). Chronic relative to initial infection often shows more substantial differences in DTI metrics related to biomarkers of infection (e.g., viral load and immune compromise), disease duration, and ART duration (Wright et al., 2015; Cordero et al., 2017; Strain et al., 2017), which complicates attempts to distinguish effects of age, as age is often correlated with the duration of infection and ART.

Most DTI studies report independent effects of age and HIV on DTI metrics, but no evidence for an interaction (Gongvatana et al., 2011; Towgood et al., 2011), even in subjects over the age of 60 (Nir et al., 2014). Instead, for example, longer HIV duration may interact with the presence of the apolipoprotein E4 allele (which increases the risk for Alzheimer's disease) (Jahanshad et al., 2012; Wendelken et al., 2016) or impaired glucose metabolism (Nakamoto et al., 2012) to compromise the brain in older HIV-infected individuals. A single study reported significant age by HIV interactions for decreased FA in the posterior limbs of the internal capsules, cerebral peduncles, and anterior corona radiata in HIV+ relative to seronegative control participants (Seider et al., 2016); HIV duration as measured by time since diagnosis was not a significant predictor of white matter damage in the described cohort suggesting that the reported interaction truly reflected the effects of aging. Support for an interactive effect of aging and HIV on DTI metrics comes from a longitudinal DTI study suggesting greater than normal age-related changes on the genu of HIV patients at 1 year follow up (Chang et al., 2008). A more recent longitudinal study, with an approximate 2-year follow-up interval, did not show differences in metrics between the first and second evaluation (Corrêa et al., 

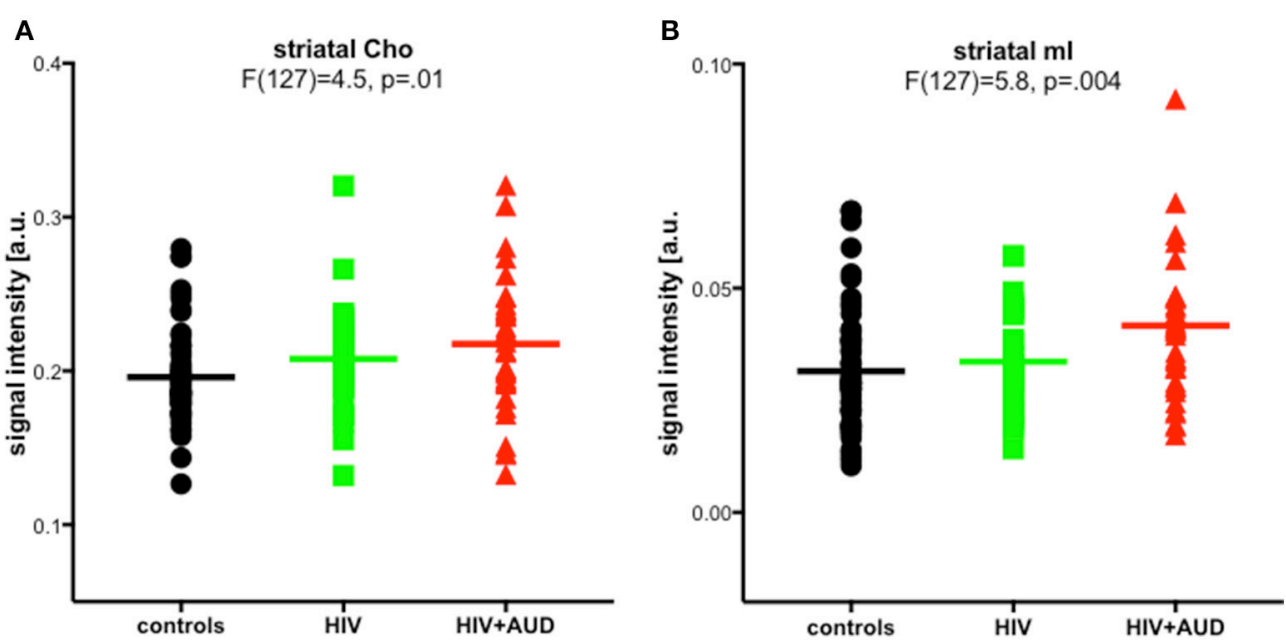

FIGURE 4 | Striatal choline-containing compounds (Cho) and myo-Inositol (ml) levels across 3 groups (controls, HIV, HIV+AUD). Reprinted from Zahr et al. (2014) with permission from John Wiley and Sons.

2016b), possibly because viremia was better controlled in the later study.

Although widespread abnormalities in white matter microstructure correlate with general cognitive compromise in HIV (Nir et al., 2014; Strain et al., 2017; Underwood et al., 2017a; Watson et al., 2017), more specific microstructure/function relationships have also been reported. For example, planning deficits correlated with low FA in anterior thalamic radiations, inferior fronto-occiptal fasciculi, superior longitudinal fascicule, corpus callosum genu, and uncinate fascicule (Corrêa et al., 2015); motor impairments correlated with low FA in various motor tracts (Bernard et al., 2013); self-reported signs of peripheral neuropathy correlated with abnormally high callosal diffusivity (Pfefferbaum et al., 2009a).

DTI has revealed microstructural damage related to alcoholism in cerebral areas that appear intact in structural MRI analyses (e.g., Pfefferbaum and Sullivan, 2002; Sullivan et al., 2003; Pfefferbaum et al., 2006). Quantitative fiber tracking has demonstrated in alcoholics compared with controls greater FA deficits in anterior than in posterior fibers of supratentorial and infratentorial white matter bundles as well as low FA in tracts of the corpus callosum, centrum semiovale, internal and external capsules, fornix, superior cingulate, longitudinal fasciculi (Pfefferbaum et al., 2000, 2002b, 2009b; Pfefferbaum and Sullivan, 2005; Müller-Oehring et al., 2009; Trivedi et al., 2013; Fortier et al., 2014).

Quantitative analysis DTI data from cross-sectional study of 4-groups (controls, AUD, HIV, HIV+AUD) revealed in all patient groups relative to controls lower integrity of callosal regions (Pfefferbaum et al., 2007) and uncinate fasciculus (Schulte et al., 2012): degradation of callosal microstructure showed evidence for compounded AUD+HIV effects (Pfefferbaum et al., 2007).

In $\mathrm{HCV}$, FA has been reported as low in fiber tracks including the corpus callosum, middle cerebellar peduncles (Bladowska et al., 2013), external capsules, fronto-occipital fasiculi (Bladowska et al., 2013; Thames et al., 2015), longitudinal fasciculi (Bladowska et al., 2013; Kuhn et al., 2017), and corona radiata (Kuhn et al., 2017). Studies of HIV+HCV coinfection show greater brain-wide diffusivity with voxel-based analysis (Stebbins et al., 2007) and higher diffusivity and lower FA by region-of-interest analysis (Gongvatana et al., 2011). A study evaluating co-infection on corpus callosum microstructure reported no additive effects (Heaps-Woodruff et al., 2016), whereas another study using TBSS noted compromise of the corona radiata in HIV + HCV co-infection (Seider et al., 2016).

\section{SUMMARY AND CONCLUSIONS}

Getting old with HIV appears to cause premature aging with respect to medical conditions, psychiatric comorbidities, and neurocognitive performance. Structural MRI findings suggest accelerated aging of select brain gray matter volumes, but equivocal evidence for an interactive increase in $\mathrm{WMH}$ burden in older HIV-infected individuals. Current DTI studies are similarly conflicting as to whether older age and HIV have interactive effects on white matter integrity. The literature remains sparse with respect to longitudinal studies, which will help distinguish between healthy, premature, and accelerated aging with HIV.

ART has largely controlled the HIV epidemic, but fundamental questions regarding the precise cause of neurocognitive dysfunction in HIV remain. In the postART era, persistent issues related to an aging HIV population include effects of common comorbid conditions, such as AUD and HCV infection. Neuroimaging points to the sensitivity of the thalamus to HIV infection. High-resolution imaging and segmentation of thalamic substructures may provide a more refined understanding of the substrates underlying cognitive decline in HIV. DTI has been underutilized in studying the HIV brain and thus also holds promise for clarifying the brain regions involved in HIV-associated cognitive and motor impairments and in explicating mechanisms that may contribute to dysfunction with age. Free water imaging, a DTI analysis method that improves the specificity and sensitivity of DTI 
by accounting for extracellular water (Pasternak et al., 2009, 2012; Metzler-Baddeley et al., 2012), may permit a better understanding of neuroinflammatory processes in HIV (Strain et al., 2017) and aging. A better understanding of the aging HIV brain will help in the development of integrated healthcare approaches for these complicated patients.

\section{AUTHOR CONTRIBUTIONS}

NMZ envisioned and wrote this review manuscript and is accountable for all aspects of the work.

\section{REFERENCES}

Adinolfi, L. E., Nevola, R., Lus, G., Restivo, L., Guerrera, B., Romano, C., et al. (2015). Chronic hepatitis C virus infection and neurological and psychiatric disorders: an overview. World J. Gastroenterol. 21, 2269-2280. doi: 10.3748/wjg.v21.i8.2269

Adoukonou, T. A., Kouna-Ndouongo, P., Kpangon, A., Gnonlonfoun, D., Kpacha, B., Dovonou, A., et al. (2017). Distal sensory polyneuropathy among HIVinfected patients at Parakou University Hospital, Benin, 2011. Med. Sante Trop. 27, 190-194. doi: 10.1684/mst.2017.0685

Ances, B. M., Ortega, M., Vaida, F., Heaps, J., and Paul, R. (2012). Independent effects of HIV, aging, and HAART on brain volumetric measures. $J$ Acquir Immune Defic Syndr 59, 469-477. doi: 10.1097/QAI.0b013e31824 $9 \mathrm{db} 17$

Anstey, K. J., Jorm, A. F., Reglade-Meslin, C., Maller, J., Kumar, R., von Sanden, C., et al. (2006). Weekly alcohol consumption, brain atrophy, and white matter hyperintensities in a community-based sample aged 60 to 64 years. Psychosom. Med. 68, 778-785. doi: 10.1097/01.psy.0000237779.56500.af

Antinori, A., Arendt, G., Becker, J. T., Brew, B. J., Byrd, D. A., Cherner, M., et al. (2007). Updated research nosology for HIVassociated neurocognitive disorders. Neurology 69, 1789-1799. doi: 10.1212/01.WNL.0000287431.88658.8b

Arentoft, A., Byrd, D., Monzones, J., Coulehan, K., Fuentes, A., Rosario, A., et al. (2015). Socioeconomic status and neuropsychological functioning: associations in an ethnically diverse HIV+ cohort. Clin. Neuropsychol. 29, 232-254. doi: $10.1080 / 13854046.2015 .1029974$

Arentzen, M., Jubt, F., Evers, S., Hesselmann, V., Fiori, W., Reichelt, D., et al. (2015). Cerebrovascular events in HIV-infected patients: an analysis of a cohort of 3203 HIV + patients during the times of cART. Int. J. Neurosci. 125, 601-611. doi: $10.3109 / 00207454.2014 .956870$

Asnis, G. M., and Migdal, A. L. (2005). Neuropsychiatric impact of hepatitis C on advanced HIV. Neurology 64:768. doi: 10.1212/WNL.64.4.768

Aylward, E. H., Henderer, J. D., McArthur, J. C., Brettschneider, P. D., Harris, G. J., Barta, P. E., et al. (1993). Reduced basal ganglia volume in HIV-1-associated dementia: results from quantitative neuroimaging. Neurology 43, 2099-2104. doi: 10.1212/WNL.43.10.2099

Bairwa, D., Kumar, V., Vyas, S., Das, B. K., Srivastava, A. K., Pandey, R. M., et al. (2016). Case control study: magnetic resonance spectroscopy of brain in HIV infected patients. BMC Neurol. 16:99. doi: 10.1186/s12883-016-0628-x

Barron, D. S., Tandon, N., Lancaster, J. L., and Fox, P. T. (2014). Thalamic structural connectivity in medial temporal lobe epilepsy. Epilepsia 55, e50-e55. doi: 10.1111/epi.12637

Becker, J. T., Martinson, J. J., Penugonda, S., Kingsley, L., Molsberry, S., Reynolds, S., et al. (2015). No association between Apoepsilon4 alleles, HIV infection, age, neuropsychological outcome, or death. J. Neurovirol. 21, 24-31. doi: $10.1007 / \mathrm{s} 13365-014-0290-2$

Becker, J. T., Maruca, V., Kingsley, L. A., Sanders, J. M., Alger, J. R., Barker, P. B., et al. (2012). Factors affecting brain structure in men with HIV disease in the post-HAART era. Neuroradiology 54, 113-121. doi: 10.1007/s00234-0110854-2

Behrens, T. E., Johansen-Berg, H., Woolrich, M. W., Smith, S. M., WheelerKingshott, C. A., Boulby, P. A., et al. (2003). Non-invasive mapping of

\section{FUNDING}

This study was supported with grant funding from the National Institute of Alcohol Abuse and Alcoholism (NIAAA): AA017347, AA017168, and AA013521.

\section{ACKNOWLEDGMENTS}

NMZ would like to acknowledge Drs. Adolf Pfefferbaum and Edith V. Sullivan for supporting this work and reviewing in-progress versions of the manuscript.

connections between human thalamus and cortex using diffusion imaging. Nat. Neurosci. 6, 750-757. doi: 10.1038/nn1075

Bendszus, M., Weijers, H. G., Wiesbeck, G., Warmuth-Metz, M., Bartsch, A. J., Engels, S., et al. (2001). Sequential MR imaging and proton MR spectroscopy in patients who underwent recent detoxification for chronic alcoholism: correlation with clinical and neuropsychological data. Am. J. Neuroradiol. 22, 1926-1932.

Benevides, M. L. A. C. S. E., Filho, S. B., Debona, R., Bergamaschi, E. N., and Nunes, J. C. (2017). Prevalence of peripheral neuropathy and associated factors in HIV-infected patients. J. Neurol. Sci. 375, 316-320. doi: 10.1016/j.jns.2017. 02.011

Bernard, C., Dilharreguy, B., Allard, M., Amieva, H., Bonnet, F., Dauchy, F., et al. (2013). Muscular weakness in individuals with HIV associated with a disorganization of the cortico-spinal tract: a multi-modal MRI investigation. PLoS ONE 8:e66810. doi: 10.1371/journal.pone.0066810

Bezerra, M. L., Harumi, J. A., Shinosaki, J. S., Pedroso, J. L., Henriques de Aquino C. C., de Souza, L. T., et al. (2011). Hepatitis C virus: a rare manifestationremitting relapsing central and peripheral demyelination. Neurol. India 59, 114-116. doi: 10.4103/0028-3886.76889

Birbal, S., Dheda, M., Ojewole, E., and Oosthuizen, F. (2016). Adverse drug reactions associated with antiretroviral therapy in South Africa. Afr. J. AIDS Res. 15, 243-248. doi: 10.2989/16085906.2016.1191519

Bladowska, J., Knysz, B., Zimny, A., Malyszczak, K., Koltowska, A., Szewczyk, P., et al. (2014). Value of perfusion-weighted MR imaging in the assessment of early cerebral alterations in neurologically asymptomatic HIV-1-positive and HCV-positive patients. PLOS ONE 9:e102214. doi: 10.1371/journal.pone.0102214

Bladowska, J., Zimny, A., Knysz, B., Malyszczak, K., Koltowska, A., Szewczyk, P., et al. (2013). Evaluation of early cerebral metabolic, perfusion and microstructural changes in HCV-positive patients: a pilot study. J. Hepatol. 59, 651-657. doi: 10.1016/j.jhep.2013.05.008

Bokemeyer, M., Ding, X. Q., Goldbecker, A., Raab, P., Heeren, M., Arvanitis, D., et al. (2011). Evidence for neuroinflammation and neuroprotection in HCV infection-associated encephalopathy. Gut 60, 370-377. doi: 10.1136/gut.2010.217976

Bonacini, M. (2011). Alcohol use among patients with HIV infection. Ann. Hepatol. 10, 502-507.

Bonnet, F., Amieva, H., Marquant, F., Bernard, C., Bruyand, M., Dauchy, F. A., et al. (2013). Cognitive disorders in HIV-infected patients: are they HIV-related? AIDS 27, 391-400. doi: 10.1097/QAD.0b013e32835 b1019

Boutte, D., Calhoun, V. D., Chen, J., Sabbineni, A., Hutchison, K., and Liu, J. (2012). Association of genetic copy number variations at $11 \mathrm{q} 14.2$ with brain regional volume differences in an alcohol use disorder population. Alcohol 46, 519-527. doi: 10.1016/j.alcohol.2012.05.002

Braithwaite, R. S., Conigliaro, J., Roberts, M. S., Shechter, S., Schaefer, A., McGinnis, K., et al. (2007). Estimating the impact of alcohol consumption on survival for HIV+ individuals. AIDS Care 19, 459-466. doi: 10.1080/09540120601095734

Brand, A., Richter-Landsberg, C., and Leibfritz, D. (1993). NMR studies on the energy metabolism of glial and neuronal cells. Dev. Neurosci. 15, 289-298. doi: $10.1159 / 000111347$ 
Brew, B. J., and Chan, P. (2014). Update on HIV dementia and HIVassociated neurocognitive disorders. Curr. Neurol. Neurosci. Rep. 14:468. doi: 10.1007/s11910-014-0468-2

Brooks, J. T., Buchacz, K., Gebo, K. A., and Mermin, J. (2012). HIV infection and older Americans: the public health perspective. Am. J. Public Health 102, 1516-1526. doi: 10.2105/AJPH.2012.300844

Butt, A. A., McGinnis, K., Rodriguez-Barradas, M. C., Crystal, S., Simberkoff, M., Goetz, M. B., et al. (2009). HIV infection and the risk of diabetes mellitus. AIDS 23, 1227-1234. doi: 10.1097/QAD.0b013e32832bd7af

Caldwell, J. Z., Gongvatana, A., Navia, B. A., Sweet, L. H., Tashima, K., Ding, M., et al. (2014). Neural dysregulation during a working memory task in human immunodeficiency virus-seropositive and hepatitis $\mathrm{C}$ coinfected individuals. J. Neurovirol. 20, 398-411. doi: 10.1007/s13365-014-0 257-3

Capuron, L., Pagnoni, G., Demetrashvili, M., Woolwine, B. J., Nemeroff, C. B., Berns, G. S., et al. (2005). Anterior cingulate activation and error processing during interferon-alpha treatment. Biol. Psychiatry 58, 190-196. doi: 10.1016/j.biopsych.2005.03.033

Cardenas, V. A., Studholme, C., Gazdzinski, S., Durazzo, T. C., and Meyerhoff, D. J. (2007). Deformation-based morphometry of brain changes in alcohol dependence and abstinence. Neuroimage 34, 879-887. doi: 10.1016/j.neuroimage.2006.10.015

Cardenas, V. A., Studholme, C., Meyerhoff, D. J., Song, E., and Weiner, M. W. (2005). Chronic active heavy drinking and family history of problem drinking modulate regional brain tissue volumes. Psychiatry Res. 138, 115-130. doi: 10.1016/j.pscychresns.2005.01.002

Cardenas, V. A., Meyerhoff, D., Studholme, C., Kornak, J., Rothlind, J., Lampiris, H., et al. (2009). Evidence for ongoing brain injury in human immunodeficiency virus-positive patients treated with antiretroviral therapy. J. Neurovirol. 15, 324-333. doi: 10.1080/13550280902973960

Casato, M., Saadoun, D., Marchetti, A., Limal, N., Picq, C., Pantano, P., et al. (2005). Central nervous system involvement in hepatitis C virus cryoglobulinemia vasculitis: a multicenter case-control study using magnetic resonance imaging and neuropsychological tests. J. Rheumatol. 32, 484-488.

Castillo, D., Ernst, T., Cunningham, E., and Chang, L. (2017). Altered associations between pain symptoms and brain morphometry in the pain matrix of HIV-seropositive individuals. J. Neuroimmune Pharmacol. 3, 77-89. doi: 10.1007/s11481-017-9762-5

Cattie, J. E., Letendre, S. L., Woods, S. P., Barakat, F., Perry, W., Cherner, M., et al. R. C. G. (2014). Persistent neurocognitive decline in a clinic sample of hepatitis $\mathrm{C}$ virus-infected persons receiving interferon and ribavirin treatment. J. Neurovirol. 20, 561-570. doi: 10.1007/s13365-014-0265-3

Center for Disease Control and Prevention (2015). Diagnoses of HIV Infection in the United States and Dependent Areas, 2014. HIV Surveillance Report.

Center for Disease Control and Prevention (2016a). Diagnoses of HIV Infection Among Adults Aged 50 Years and Older in the United States and Dependent Areas, 2010-2014. HIV Surveillance Supplemental Report.

Center for Disease Control and Prevention (2016b). Monitoring Selected National HIV Prevention and Care Objectives by Using HIV Surveillance Data: United States and 6 Dependent Areas, 2014. HIV Surveillance Supplemental Report, 2016.

Center for Disease Control and Prevention (2011). HIV Aand Viral Hepatitis. Available online at: https://www.cdc.gov/hiv/pdf/library/factsheets/hiv-viralhepatitis.pdf

Center for Disease Control and Prevention (2013). The National Vital Statistics Report "Deaths: Final Data for 2013." Available online at: http://www.cdc.gov/ nchs/data_access/Vitalstatsonline.htm

Chamie, G., Bonacini, M., Bangsberg, D. R., Stapleton, J. T., Hall, C., Overton, E. T., et al. (2007). Factors associated with seronegative chronic hepatitis $C$ virus infection in HIV infection. Clin. Infect. Dis. 44, 577-583. doi: 10.1086/ 511038

Chang, L., Ernst, T., Leonido-Yee, M., Walot, I., and Singer, E. (1999). Cerebral metabolite abnormalities correlate with clinical severity of HIV-1 cognitive motor complex. Neurology 52, 100-108. doi: 10.1212/WNL.52.1.100

Chang, L., Ernst, T., Witt, M. D., Ames, N., Gaiefsky, M., and Miller, E. (2002). Relationships among brain metabolites, cognitive function, and viral loads in antiretroviral-naive HIV patients. Neuroimage 17, 1638-1648. doi: $10.1006 /$ nimg.2002.1254
Chang, L., Jiang, C., Cunningham, E., Buchthal, S., Douet, V., Andres, M., et al. (2014). Effects of APOE epsilon4, age, and HIV on glial metabolites and cognitive deficits. Neurology 82, 2213-2222. doi: 10.1212 /WNL.0000000000000526

Chang, L., Munsaka, S. M., Kraft-Terry, S., and Ernst, T. (2013). Magnetic resonance spectroscopy to assess neuroinflammation and neuropathic pain. J. Neuroimmune Pharmacol. 8, 576-593. doi: 10.1007/s11481-013-9460-x

Chang, L., Wong, V., Nakama, H., Watters, M., Ramones, D., Miller, E. N., et al. (2008). Greater than age-related changes in brain diffusion of HIV patients after 1 year. J. Neuroimmune Pharmacol. 3, 265-274. doi: $10.1007 /$ s11481-008-9120-8

Chanraud, S., Leroy, C., Martelli, C., Kostogianni, N., Delain, F., Aubin, H. J., et al. (2009a). Episodic memory in detoxified alcoholics: contribution of grey matter microstructure alteration. PLOS ONE 4:e6786. doi: 10.1371/journal.pone.0006786

Chanraud, S., Martelli, C., Delain, F., Kostogianni, N., Douaud, G., Aubin, H. J., et al. (2007). Brain morphometry and cognitive performance in detoxified alcohol-dependents with preserved psychosocial functioning. Neuropsychopharmacology 32, 429-438. doi: 10.1038/sj.npp.1301219

Chanraud, S., Reynaud, M., Wessa, M., Penttila, J., Kostogianni, N., Cachia, A., et al. (2009b). Diffusion tensor tractography in mesencephalic bundles: relation to mental flexibility in detoxified alcohol-dependent subjects. Neuropsychopharmacology 34, 1223-1232. doi: 10.1038/npp.2008.101

Chen, Y., An, H., Zhu, H., Stone, T., Smith, J. K., Hall, C., et al. (2009). White matter abnormalities revealed by diffusion tensor imaging in nondemented and demented HIV+ patients. Neuroimage 47, 1154-1162. doi: 10.1016/j.neuroimage.2009.04.030

Cherner, M., Letendre, S., Heaton, R. K., Durelle, J., Marquie-Beck, J., Gragg, B., et al. (2005). Hepatitis C augments cognitive deficits associated with HIV infection and methamphetamine. Neurology 64, 1343-1347. doi: 10.1212/01.WNL.0000158328.26897.0D

Chong, W. K., Sweeney, B., Wilkinson, I. D., Paley, M., Hall-Craggs, M. A., Kendall, B. E., et al. (1993). Proton spectroscopy of the brain in HIV infection: correlation with clinical, immunologic, and MR imaging findings. Radiology 188, 119-124. doi: 10.1148/radiology.188.1.8099750

Chopra, K., and Tiwari, V. (2012). Alcoholic neuropathy: possible mechanisms and future treatment possibilities. Br. J. Clin. Pharmacol. 73, 348-362. doi: 10.1111/j.1365-2125.2011.04111.x

Ciccarelli, N., Fabbiani, M., Di Giambenedetto, S., Fanti, I., Baldonero, E., Bracciale, L., et al. (2011). Efavirenz associated with cognitive disorders in otherwise asymptomatic HIV-infected patients. Neurology 76, 1403-1409. doi: 10.1212/WNL.0b013e31821670fb

Clark, U. S., Walker, K. A., Cohen, R. A., Devlin, K. N., Folkers, A. M., Pina, M. J., et al. (2015). Facial emotion recognition impairments are associated with brain volume abnormalities in individuals with HIV. Neuropsychologia 70, 263-271. doi: 10.1016/j.neuropsychologia.2015.03.003

Clifford, D. B., Vaida, F., Kao, Y. T., Franklin, D. R., Letendre, S. L., Collier, A. C., et al. (2015). Absence of neurocognitive effect of hepatitis C infection in HIV-coinfected people. Neurology 84, 241-250. doi: 10.1212/WNL.0000000000001156

Clifford, K. M., Samboju, V., Cobigo, Y., Milanini, B., Marx, G. A., Hellmuth, J. M., et al. (2017). Progressive Brain Atrophy Despite Persistent Viral Suppression in HIV Over Age 60. J. Acquir. Immune Defic. Syndr. 76, 289-297. doi: 10.1097/QAI.0000000000001489

Cole, J. H., Underwood, J., Caan, M. W., De Francesco, D., van Zoest, R. A., Leech, R., et al. (2017). Increased brain-predicted aging in treated HIV disease. Neurology 88, 1349-1357. doi: 10.1212/WNL.0000000000003790

Conigliaro, J., Justice, A. C., Gordon, A. J., and Bryant, K. (2006). Role of alcohol in determining human immunodeficiency virus (HIV)-relevant outcomes: a conceptual model to guide the implementation of evidence-based interventions into practice. Med. Care 44, S1-S6. doi: 10.1097/01.mlr.0000223659. 36369.cf

Cook, R. L., Sereika, S. M., Hunt, S. C., Woodward, W. C., Erlen, J. A., and Conigliaro, J. (2001). Problem drinking and medication adherence among persons with HIV infection. J. Gen. Intern. Med. 16, 83-88. doi: 10.1111/j.1525-1497.2001.00122.x

Cordero, D. M., Towe, S. L., Chen, N. K., Robertson, K. R., Madden, D. J., Huettel, S. A., et al. (2017). Cocaine dependence does not contribute substantially 
to white matter abnormalities in HIV infection. J. Neurovirol. 23, 441-450. doi: 10.1007/s13365-017-0512-5

Córdoba, J., Flavia, M., Jacas, C., Sauleda, S., Esteban, J. I., Vargas, V., et al. (2003). Quality of life and cognitive function in hepatitis $C$ at different stages of liver disease. J. Hepatol. 39, 231-238. doi: 10.1016/S0168-8278(03)00189-2

Corrêa, D. G., Zimmermann, N., Doring, T. M., Wilner, N. V., Leite, S. C., Cabral, R. F., et al. (2015). Diffusion tensor MR imaging of white matter integrity in HIV-positive patients with planning deficit. Neuroradiology 57, 475-482. doi: 10.1007/s00234-015-1489-5

Corrêa, D. G., Zimmermann, N., Netto, T. M., Tukamoto, G., Ventura, N., de Castro Bellini Leite, S., et al. (2016a). Regional cerebral gray matter volume in HIV-positive patients with executive function deficits. J. Neuroimaging 26, 450-457. doi: 10.1111/jon.12327

Corrêa, D. G., Zimmermann, N., Tukamoto, G., Doring, T., Ventura, N., Leite, S. C., et al. (2016b). Longitudinal assessment of subcortical gray matter volume, cortical thickness, and white matter integrity in HIV-positive patients. J. Magn. Reson. Imaging 44, 1262-1269. doi: 10.1002/jmri.25263

Cysique, L. A., Maruff, P., and Brew, B. J. (2006). The neuropsychological profile of symptomatic AIDS and ADC patients in the pre-HAART era: a meta-analysis. J. Int. Neuropsychol. Soc. 12, 368-382. doi: 10.1017/S1355617706060401

Cysique, L. A., Moffat, K., Moore, D. M., Lane, T. A., Davies, N. W., Carr, A., et al. (2013). HIV, vascular and aging injuries in the brain of clinically stable HIV-infected adults: a (1)H MRS study. PLoS ONE 8:e61738. doi: 10.1371/journal.pone.0061738

Dawes, S., Suarez, P., Casey, C. Y., Cherner, M., Marcotte, T. D., Letendre, S., et al. (2008). Variable patterns of neuropsychological performance in HIV-1 infection. J. Clin. Exp. Neuropsychol. 30, 613-626. doi: 10.1080/13803390701565225

Day, J. J., Grant, I., Atkinson, J. H., Brysk, L. T., McCutchan, J. A., Hesselink, J. R., et al. (1992). Incidence of AIDS dementia in a two-year follow-up of AIDS and ARC patients on an initial phase II AZT placebo-controlled study: San Diego cohort. J. Neuropsychiatry Clin. Neurosci. 4, 15-20. doi: 10.1176/jnp.4.1.15

De Bellis, M. D., Narasimhan, A., Thatcher, D. L., Keshavan, M. S., Soloff, P., and Clark, D. B. (2005). Prefrontal cortex, thalamus, and cerebellar volumes in adolescents and young adults with adolescent-onset alcohol use disorders and comorbid mental disorders. Alcohol. Clin. Exp. Res. 29, 1590-1600. doi: 10.1097/01.alc.0000179368.87886.76

Deistung, A., Schafer, A., Schweser, F., Biedermann, U., Turner, R., and Reichenbach, J. R. (2013). Toward in vivo histology: a comparison of quantitative susceptibility mapping (QSM) with magnitude-, phase-, and R2*-imaging at ultra-high magnetic field strength. Neuroimage 65, 299-314. doi: 10.1016/j.neuroimage.2012.09.055

Deoni, S. C., Rutt, B. K., Parrent, A. G., and Peters, T. M. (2007). Segmentation of thalamic nuclei using a modified k-means clustering algorithm and highresolution quantitative magnetic resonance imaging at $1.5 \mathrm{~T}$. Neuroimage 34 , 117-126. doi: 10.1016/j.neuroimage.2006.09.016

Desquilbet, L., Jacobson, L. P., Fried, L. P., Phair, J. P., Jamieson, B. D., Holloway, M., et al. (2007). HIV-1 infection is associated with an earlier occurrence of a phenotype related to frailty. J. Gerontol. A Biol. Sci. Med. Sci. 62, 1279-1286. doi: $10.1093 /$ gerona/62.11.1279

Devlin, K. N., Gongvatana, A., Clark, U. S., Chasman, J. D., Westbrook, M. L., Tashima, K. T., et al. (2012). Neurocognitive effects of HIV, hepatitis C, and substance use history. J. Int. Neuropsychol. Soc. 18, 68-78. doi: $10.1017 / S 1355617711001408$

Dewey, J., Hana, G., Russell, T., Price, J., McCaffrey, D., Harezlak, J., et al. (2010). Reliability and validity of MRI-based automated volumetry software relative to auto-assisted manual measurement of subcortical structures in HIV-infected patients from a multisite study. Neuroimage 51, 1334-1344. doi: 10.1016/j.neuroimage.2010.03.033

Di Sclafani, V., Mackay, R. D., Meyerhoff, D. J., Norman, D., Weiner, M. W., and Fein, G. (1997). Brain atrophy in HIV infection is more strongly associated with CDC clinical stage than with cognitive impairment. J. Int. Neuropsychol. Soc. 3, 276-287.

Dragovic, G., and Jevtovic, D. (2003). Nucleoside reverse transcriptase inhibitor usage and the incidence of peripheral neuropathy in HIV/AIDS patients. Antivir. Chem. Chemother. 14, 281-284. doi: 10.1177/095632020301400507

du Plessis, S., Vink, M., Joska, J. A., Koutsilieri, E., Bagadia, A., Stein, D. J., et al. (2016). Prefrontal cortical thinning in HIV infection is associated with impaired striatal functioning. J. Neural Transm. 123, 643-651. doi: 10.1007/s00702-016-1571-0

Du, H., Wu, Y., Ochs, R., Edelman, R. R., Epstein, L. G., McArthur, J., et al. (2012). A comparative evaluation of quantitative neuroimaging measurements of brain status in HIV infection. Psychiatry Res. 203, 95-99. doi: 10.1016/j.pscychresns.2011.08.014

Durazzo, T. C., Gazdzinski, S., Banys, P., and Meyerhoff, D. J. (2004). Cigarette smoking exacerbates chronic alcohol-induced brain damage: a preliminary metabolite imaging study. Alcohol. Clin. Exp. Res. 28, 1849-1860. doi: 10.1097/01.ALC.0000148112.92525.AC

Durazzo, T. C., Pathak, V., Gazdzinski, S., Mon, A., and Meyerhoff, D. J. (2010). Metabolite levels in the brain reward pathway discriminate those who remain abstinent from those who resume hazardous alcohol consumption after treatment for alcohol dependence. J. Stud. Alcohol Drugs 71, 278-289. doi: 10.15288/jsad.2010.71.278

Durazzo, T. C., Rothlind, J. C., Cardenas, V. A., Studholme, C., Weiner, M. W., and Meyerhoff, D. J. (2007). Chronic cigarette smoking and heavy drinking in human immunodeficiency virus: consequences for neurocognition and brain morphology. Alcohol 41, 489-501. doi: 10.1016/j.alcohol.2007.07.007

Effros, R. B., Fletcher, C. V., Gebo, K., Halter, J. B., Hazzard, W. R., Horne, F. M., et al. (2008). Aging and infectious diseases: workshop on HIV infection and aging: what is known and future research directions. Clin. Infect. Dis. 47, 542-553. doi: $10.1086 / 590150$

Ende, G., Welzel, H., Walter, S., Weber-Fahr, W., Diehl, A., Hermann, D., et al. (2005). Monitoring the effects of chronic alcohol consumption and abstinence on brain metabolism: a longitudinal proton magnetic resonance spectroscopy study. Biol. Psychiatry 58, 974-980. doi: 10.1016/j.biopsych.2005.05.038

English, C. D., Kaufman, M. J., Worth, J. L., Babb, S. M., Drebing, C. E., Navia, B. A., et al. (1997). Elevated frontal lobe cytosolic choline levels in minimal or mild AIDS dementia complex patients: a proton magnetic resonance spectroscopy study. Biol. Psychiatry 41, 500-502. doi: 10.1016/S0006-3223(96)00475-1

Evans, S. R., Clifford, D. B., Kitch, D. W., Goodkin, K., Schifitto, G., McArthur, J. C., et al. (2008). Simplification of the research diagnosis of HIV-associated sensory neuropathy. HIV Clin. Trials 9, 434-439. doi: 10.1310/hct0906-434

Fama, R., Eisen, J. C., Rosenbloom, M. J., Sassoon, S. A., Kemper, C. A., Deresinski, S., et al. (2007). Upper and lower limb motor impairments in alcoholism, HIV infection, and their comorbidity. Alcohol. Clin. Exp. Res. 31, 1038-1044. doi: 10.1111/j.1530-0277.2007.00385.x

Fama, R., Rosenbloom, M. J., Nichols, B. N., Pfefferbaum, A., and Sullivan, E. V. (2009). Working and episodic memory in HIV infection, alcoholism, and their comorbidity: baseline and 1-year follow-up examinations. Alcohol. Clin. Exp. Res. 33, 1815-1824. doi: 10.1111/j.1530-0277.2009.01020.x

Fama, R., Rosenbloom, M. J., Sassoon, S. A., Pfefferbaum, A., and Sullivan, E. V. (2012). Differential effect of alcoholism and HIV infection on visuomotor procedural learning and retention. Alcohol. Clin. Exp. Res. 36, 1738-1747. doi: 10.1111/j.1530-0277.2012.01790.x

Fama, R., Rosenbloom, M. J., Sassoon, S. A., Rohlfing, T., Pfefferbaum, A., and Sullivan, E. V. (2014). Thalamic volume deficit contributes to procedural and explicit memory impairment in HIV infection with primary alcoholism comorbidity. Brain Imaging Behav. 8, 611-620. doi: 10.1007/s11682-0139286-4

Fama, R., Rosenbloom, M. J., Sassoon, S. A., Thompson, M. A., Pfefferbaum, A., and Sullivan, E. V. (2011). Remote semantic memory for public figures in HIV infection, alcoholism, and their comorbidity. Alcohol. Clin. Exp. Res. 35, 265-276. doi: 10.1111/j.1530-0277.2010.01342.x

Fama, R., Sullivan, E. V., Sassoon, S. A., Pfefferbaum, A., and Zahr, N. M. (2016). Impairments in component processes of executive function and episodic memory in alcoholism, HIV infection, and HIV infection with alcoholism comorbidity. Alcohol. Clin. Exp. Res. 40, 2656-2666. doi: 10.1111/acer.13250

Fein, G., Landman, B., Tran, H., McGillivray, S., Finn, P., Barakos, J., et al. (2006). Brain atrophy in long-term abstinent alcoholics who demonstrate impairment on a simulated gambling task. Neuroimage 32, 1465-1471. doi: 10.1016/j.neuroimage.2006.06.013

Fein, G., Meyerhoff, D., Di Sclafani, V., Ezekiel, F., Poole, N., MacKay, S., et al. and Weiner, M. W. (1994). "1H magnetic resonance spectroscopic imaging separates neuronal from glial changes in alcohol-related brain atrophy," in Alcohol and Glial Cells, NIAAA Research Monograph \# 27, ed F. Lancaster (Bethesda, MD: US Government Printing Office), 227-241. 
Fennema-Notestine, C., Ellis, R. J., Archibald, S. L., Jernigan, T. L., Letendre, S. L., Notestine, R. J., et al. (2013). Increases in brain white matter abnormalities and subcortical gray matter are linked to CD4 recovery in HIV infection. J. Neurovirol. 19, 393-401. doi: 10.1007/s13365-013-0185-7

Foley, J. M., Gooding, A. L., Thames, A. D., Ettenhofer, M. L., Kim, M. S., Castellon, S. A., et al. (2013). Visuospatial and Attentional Abilities Predict Driving Simulator Performance Among Older HIV-infected Adults. Am. J. Alzheimers Dis. Other Demen. 28, 185-194. doi: 10.1177/1533317512473192

Foley, J., Ettenhofer, M., Wright, M., and Hinkin, C. H. (2008). Emerging issues in the neuropsychology of HIV infection. Curr. HIV/AIDS Rep. 5, 204-211. doi: 10.1007/s11904-008-0029-x

Fonnum, F. (1984). Glutamate: a neurotransmitter in the mammalian brain. J. Neurochem. 42, 1-11. doi: 10.1111/j.1471-4159.1984.tb09689.x

Fortier, C. B., Leritz, E. C., Salat, D. H., Lindemer, E., Maksimovskiy, A. L., Shepel, J., et al. (2014). Widespread effects of alcohol on white matter microstructure. Alcohol. Clin. Exp. Res. 38, 2925-2933. doi: 10.1111/acer.12568

Forton, D. M., Allsop, J. M., Main, J., Foster, G. R., Thomas, H. C., and TaylorRobinson, S. D. (2001). Evidence for a cerebral effect of the hepatitis C virus. Lancet 358, 38-39. doi: 10.1016/S0140-6736(00)05270-3

Forton, D. M., Hamilton, G., Allsop, J. M., Grover, V. P., Wesnes, K., O'Sullivan, C., et al. (2008). Cerebral immune activation in chronic hepatitis C infection: a magnetic resonance spectroscopy study. J. Hepatol. 49, 316-322. doi: $10.1016 /$ j.jhep.2008.03.022

Forton, D. M., Thomas, H. C., Murphy, C. A., Allsop, J. M., Foster, G. R., Main, J., et al. (2002). Hepatitis $C$ and cognitive impairment in a cohort of patients with mild liver disease. Hepatology 35, 433-439. doi: 10.1053/jhep.2002.30688

Fritz, K., Morojele, N., and Kalichman, S. (2010). Alcohol: the forgotten drug in HIV/AIDS. Lancet 376, 398-400. doi: 10.1016/S0140-6736(10)60884-7

Fuller, B. E., Loftis, J. M., Rodriguez, V. L., McQuesten, M. J., and Hauser, P. (2009). Psychiatric and substance use disorders comorbidities in veterans with hepatitis C virus and HIV coinfection. Curr. Opin. Psychiatry 22, 401-408. doi: 10.1097/YCO.0b013e32832cadb9

Fuller, R. A., Westmoreland, S. V., Ratai, E., Greco, J. B., Kim, J. P., Lentz, M. R., et al. (2004). A prospective longitudinal in vivo $1 \mathrm{H}$ MR spectroscopy study of the SIV/macaque model of neuroAIDS. BMC Neurosci. 5:10. doi: 10.1186/1471-2202-5-10

Funes, H. A., Apostolova, N., Alegre, F., Blas-Garcia, A., Alvarez, A., MartiCabrera, M., et al. (2014). Neuronal bioenergetics and acute mitochondrial dysfunction: a clue to understanding the central nervous system side effects of efavirenz. J. Infect. Dis. 210, 1385-1395. doi: 10.1093/infdis/ jiu273

Gabbai, A. A., Castelo, A., and Oliveira, A. S. (2013). HIV peripheral neuropathy. Handb. Clin. Neurol. 115, 515-529. doi: 10.1016/B978-0-444-52902-2.00029-1

Garvey, L. J., Pavese, N., Ramlackhansingh, A., Thomson, E., Allsop, J. M., Politis, M., et al. (2012). Acute HCV/HIV coinfection is associated with cognitive dysfunction and cerebral metabolite disturbance, but not increased microglial cell activation. PLOS ONE 7:e38980. doi: 10.1371/journal.pone. 0038980

Gates, T. M., and Cysique, L. A. (2016). The chronicity of HIV infection should drive the research strategy of NeuroHIV treatment studies: a critical review. CNS Drugs 30, 53-69. doi: 10.1007/s40263-015-0302-7

Geraci, A. P., and Simpson, D. M. (2001). Neurological manifestations of HIV-1 infection in the HAART era. Compr. Ther. 27, 232-241. doi: 10.1007/s12019-001-0020-6

Gomez, D., Power, C., Gill, M. J., and Fujiwara, E. (2017). Determinants of risk-taking in HIV-associated neurocognitive disorders. Neuropsychology 31, 798-810. doi: 10.1037/neu0000366

Gongvatana, A., Cohen, R. A., Correia, S., Devlin, K. N., Miles, J., Kang, H., et al. (2011). Clinical contributors to cerebral white matter integrity in HIV-infected individuals. J. Neurovirol. 17, 477-486. doi: 10.1007/s13365-011-0055-0

Gongvatana, A., Harezlak, J., Buchthal, S., Daar, E., Schifitto, G., Campbell, T., et al. (2013). Progressive cerebral injury in the setting of chronic HIV infection and antiretroviral therapy. J. Neurovirol. 19, 209-218. doi: 10.1007/s13365-013-0162-1

Grover, V. P., Pavese, N., Koh, S. B., Wylezinska, M., Saxby, B. K., Gerhard, A., et al. (2012). Cerebral microglial activation in patients with hepatitis C: in vivo evidence of neuroinflammation. J. Viral Hepat. 19, e89-e96. doi: $10.1111 /$ j.1365-2893.2011.01510.x
Guaraldi, G., Prakash, M., Moecklinghoff, C., and Stellbrink, H. J. (2014). Morbidity in older HIV-infected patients: impact of long-term antiretroviral use. AIDS Rev.16, 75-89.

Gulick, R. M., Mellors, J. W., Havlir, D., Eron, J. J., Gonzalez, C., McMahon, D., et al. (1997). Treatment with indinavir, zidovudine, and lamivudine in adults with human immunodeficiency virus infection and prior antiretroviral therapy. N. Engl. J. Med. 337, 734-739. doi: 10.1056/NEJM199709113371102

Haddow, L. J., Dudau, C., Chandrashekar, H., Cartledge, J. D., Hyare, H., Miller, R. F., et al. (2014). Cross-sectional study of unexplained white matter lesions in HIV positive individuals undergoing brain magnetic resonance imaging. AIDS Patient Care STDS 28, 341-349. doi: 10.1089/apc.2013.0230

Hammer, S. M., Squires, K. E., Hughes, M. D., Grimes, J. M., Demeter, L. M., Currier, J. S., et al. (1997). A controlled trial of two nucleoside analogues plus indinavir in persons with human immunodeficiency virus infection and CD4 cell counts of 200 per cubic millimeter or less. AIDS Clinical Trials Group 320 Study Team. N. Engl. J. Med. 337, 725-33. doi: 10.1056/NEJM1997091133 71101

Hardy, D. J., and Vance, D. E. (2009). The neuropsychology of HIV/AIDS in older adults. Neuropsychol. Rev. 19, 263-272. doi: 10.1007/s11065-009-9087-0

Harezlak, J., Cohen, R., Gongvatana, A., Taylor, M., Buchthal, S., Schifitto, G., et al. (2014). Predictors of CNS injury as measured by proton magnetic resonance spectroscopy in the setting of chronic HIV infection and CART. J. Neurovirol. 20, 294-303. doi: 10.1007/s13365-014-0246-6

Harrison, S. A. (2008). Insulin resistance among patients with chronic hepatitis C: etiology and impact on treatment. Clin. Gastroenterol. Hepatol. 6, 864-876. doi: $10.1016 /$ j.cgh.2008.03.024

Havlik, R. J., Brennan, M., and Karpiak, S. E. (2011). Comorbidities and depression in older adults with HIV. Sex. Health 8, 551-559. doi: 10.1071/SH11017

Heaps, J. M., Joska, J., Hoare, J., Ortega, M., Agrawal, A., Seedat, S., et al. (2012). Neuroimaging markers of human immunodeficiency virus infection in South Africa. J. Neurovirol. 18, 151-156. doi: 10.1007/s13365-012-0090-5

Heaps, J. M., Sithinamsuwan, P., Paul, R., Lerdlum, S., Pothisri, M., Clifford, D., et al. (2015). Association between brain volumes and HAND in cART-naive HIV+ individuals from Thailand. J. Neurovirol. 21, 105-112. doi: 10.1007/s13365-014-0309-8

Heaps-Woodruff, J. M., Wright, P. W., Ances, B. M., Clifford, D., and Paul, R. H. (2016). The impact of human immune deficiency virus and hepatitis C coinfection on white matter microstructural integrity. J. Neurovirol. 22, 389-399. doi: 10.1007/s13365-015-0409-0

Heaton, R. K., Marcotte, T. D., Mindt, M. R., Sadek, J., Moore, D. J., Bentley, H., et al. (2004). The impact of HIV-associated neuropsychological impairment on everyday functioning. J. Int. Neuropsychol. Soc. 10, 317-331. doi: $10.1017 /$ S1355617704102130

Heckmann, J. G., Kayser, C., Heuss, D., Manger, B., Blum, H. E., and Neundorfer, B. (1999). Neurological manifestations of chronic hepatitis C. J. Neurol. 246, 486-491. doi: 10.1007/s004150050388

Hermann, D., Weber-Fahr, W., Sartorius, A., Hoerst, M., Frischknecht, U., Tunc-Skarka, N., et al. (2012). Translational magnetic resonance spectroscopy reveals excessive central glutamate levels during alcohol withdrawal in humans and rats. Biol. Psychiatry 71, 1015-1021. doi: 10.1016/j.biopsych.2011. 07.034

Hilsabeck, R. C., Castellon, S. A., and Hinkin, C. H. (2005). Neuropsychological aspects of coinfection with HIV and hepatitis C virus. Clin. Infect. Dis. 41(Suppl. 1), S38-S44. doi: 10.1086/429494

Hilsabeck, R. C., Hassanein, T. I., Carlson, M. D., Ziegler, E. A., and Perry, W. (2003). Cognitive functioning and psychiatric symptomatology in patients with chronic hepatitis C. J. Int. Neuropsychol. Soc. 9, 847-854. doi: $10.1017 /$ S1355617703960048

Hilsabeck, R. C., Perry, W., and Hassanein, T. I. (2002). Neuropsychological impairment in patients with chronic hepatitis Hepatology, C. Hepatology 35, 440-446. doi: 10.1053/jhep.2002.31257

Hines, L. J., Miller, E. N., Hinkin, C. H., Alger, J. R., Barker, P., Goodkin, K., et al. (2016). Cortical brain atrophy and intra-individual variability in neuropsychological test performance in HIV disease. Brain Imaging Behav. 10, 640-651. doi: 10.1007/s11682-015-9441-1

Hinkin, C. H., Castellon, S. A., Hardy, D. J., Granholm, E., and Siegle, G. (1999). Computerized and traditional stroop task dysfunction in HIV-1 infection. Neuropsychology 13, 306-316. doi: 10.1037/0894-4105.13.2.306 
Hinkin, C. H., Castellon, S. A., Levine, A. J., Barclay, T. R., and Singer, E. J. (2008). Neurocognition in individuals co-infected with HIV and hepatitis C. J. Addict. Dis. 27, 11-17. doi: 10.1300/J069v27n02_02

Hinkin, C. H., Hardy, D. J., Mason, K. I., Castellon, S. A., Durvasula, R. S., Lam, M. N., et al. (2004). Medication adherence in HIV-infected adults: effect of patient age, cognitive status, and substance abuse. AIDS 18(Suppl. 1), S19-S25. doi: 10.1097/00002030-200401001-00004

Hjerrild, S., Renvillard, S. G., Leutscher, P., Sorensen, L. H., Ostergaard, L., Eskildsen, S. F., et al. (2016). Reduced cerebral cortical thickness in Non-cirrhotic patients with hepatitis C. Metab. Brain Dis. 31, 311-319. doi: 10.1007/s11011-015-9752-3

Hoare, J., Fouche, J. P., Spottiswoode, B., Sorsdahl, K., Combrinck, M., Stein, D. J., et al. (2011). White-Matter damage in Clade C HIV-positive subjects: a diffusion tensor imaging study. J. Neuropsychiatry Clin. Neurosci. 23, 308-315. doi: 10.1176/jnp.23.3.jnp308

Hobkirk, A. L., Towe, S. L., Patel, P., and Meade, C. S. (2017). Food insecurity is associated with cognitive deficits among hiv-positive, but not hiv-negative, individuals in a united states sample. AIDS Behav. 21, 783-791. doi: 10.1007/s10461-016-1514-7

Holt, J. L., Kraft-Terry, S. D., and Chang, L. (2012). Neuroimaging studies of the aging HIV-1-infected brain. J. Neurovirol.18, 291-302. doi: 10.1007/s13365-012-0114-1

Howe, C. J., Cole, S. R., Ostrow, D. G., Mehta, S. H., and Kirk, G. D. (2011). A prospective study of alcohol consumption and HIV acquisition among injection drug users. AIDS 25, 221-228. doi: 10.1097/QAD.0b013e3283 $40 \mathrm{fee} 2$

Hua, X., Boyle, C. P., Harezlak, J., Tate, D. F., Yiannoutsos, C. T., Cohen, R., et al. (2013). Disrupted cerebral metabolite levels and lower nadir CD4 + counts are linked to brain volume deficits in 210 HIV-infected patients on stable treatment. Neuroimage Clin 3, 132-142. doi: 10.1016/j.nicl.2013. 07.009

Inglese, M., Li, B. S., Rusinek, H., Babb, J. S., Grossman, R. I., and Gonen, O. (2003). Diffusely elevated cerebral choline and creatine in relapsing-remitting multiple sclerosis. Magn. Reson. Med. 50, 190-195. doi: 10.1002/mrm.10481

Iriana, S., Curry, M. P., and Afdhal, N. H. (2017). Neurologic Manifestations of Hepatitis C Virus Infection. Clin. Liver Dis. 21, 535-542. doi: 10.1016/j.cld.2017.03.008

Iwasa, M., Mifuji-Moroka, R., Kuroda, M., Moroka, H., Fujita, N., Kobayashi, Y., et al. (2012). Regional reduction in gray and white matter volume in brains of cirrhotic patients: voxel-based analysis of MRI. Metab. Brain Dis. 27, 551-557. doi: 10.1007/s11011-012-9314-x

Jacks, A., Wainwright, D. A., Salazar, L., Grimes, R., York, M., Strutt, A. M., et al. (2015). Neurocognitive deficits increase risk of poor retention in care among older adults with newly diagnosed HIV infection. AIDS 29, 1711-1714. doi: 10.1097/QAD.0000000000000700

Jagannathan, N. R., Desai, N. G., and Raghunathan, P. (1996). Brain metabolite changes in alcoholism: an in vivo proton magnetic resonance spectroscopy (MRS) study. Magn. Reson. Imaging 14, 553-557. doi: 10.1016/0730-725X(96)00048-3

Jahanshad, N., Valcour, V. G., Nir, T. M., Kohannim, O., Busovaca, E., Nicolas, K., et al. (2012). Disrupted brain networks in the aging HIV+ population. Brain Connect. 2, 335-344. doi: 10.1089/brain.2012.0105-Rev

Janssen, M. A., Meulenbroek, O., Steens, S. C., Goraj, B., Bosch, M., Koopmans, P. P., et al. (2015). Cognitive functioning, wellbeing and brain correlates in HIV1 infected patients on long-term combination antiretroviral therapy. AIDS 29, 2139-2148. doi: 10.1097/QAD.0000000000000824

Jernigan, T. L., Archibald, S. L., Fennema-Notestine, C., Taylor, M. J., Theilmann, R. J., Julaton, M. D., et al. (2011). Clinical factors related to brain structure in HIV: the CHARTER study. J. Neurovirol. 17, 248-257. doi: 10.1007/s13365-011-0032-7

Jernigan, T. L., Butters, N., DiTraglia, G., Schafer, K., Smith, T., Irwin, M., et al. (1991). Reduced cerebral grey matter observed in alcoholics using magnetic resonance imaging. Alcohol. Clin. Exp. Res. 15, 418-427. doi: 10.1111/j.1530-0277.1991.tb00540.x

Jiang, X., Barasky, R., Olsen, H., Riesenhuber, M., and Magnus, M. (2016). Behavioral and neuroimaging evidence for impaired executive function in "cognitively normal" older HIV-infected adults. AIDS Care 28, 436-440. doi: $10.1080 / 09540121.2015 .1112347$
Johnson, T., and Nath, A. (2010). Neurological complications of immune reconstitution in HIV-infected populations. Ann. N. Y. Acad. Sci. 1184, 106-120. doi: 10.1111/j.1749-6632.2009.05111.x

Joseph, J., Colosi, D. A., and Rao, V. R. (2016). HIV-1 induced CNS dysfunction: current overview and research priorities. Curr. HIV Res. 14, 389-399. doi: 10.2174/1570162X14666160324124940

Kallianpur, K. J., Kirk, G. R., Sailasuta, N., Valcour, V., Shiramizu, B., Nakamoto, B. K., et al. (2012). Regional cortical thinning associated with detectable levels of HIV DNA. Cereb. Cortex 22, 2065-2075. doi: 10.1093/cercor/bhr285

Kallianpur, K. J., Sakoda, M., Gangcuangco, L. M., Ndhlovu, L. C., Umaki, T., Chow, D., et al. (2016). Frailty Characteristics in Chronic HIV Patients are Markers of White Matter Atrophy Independently of Age and Depressive Symptoms: A Pilot Study. Open Med. J. 3, 138-152. doi: $10.2174 / 1874220301603010138$

Kallianpur, K. J., Shikuma, C., Kirk, G. R., Shiramizu, B., Valcour, V., Chow, D., et al. (2013). Peripheral blood HIV DNA is associated with atrophy of cerebellar and subcortical gray matter. Neurology 80, 1792-1799. doi: 10.1212/WNL.0b013e318291903f

Karaivazoglou, K., Assimakopoulos, K., Thomopoulos, K., Theocharis, G., Messinis, L., Sakellaropoulos, G., et al. (2007). Neuropsychological function in Greek patients with chronic hepatitis C. Liver Int. 27, 798-805. doi: 10.1111/j.1478-3231.2007.01486.x

Kelso, N. E., Sheps, D. S., and Cook, R. L. (2015). The association between alcohol use and cardiovascular disease among people living with HIV: a systematic review. Am. J. Drug Alcohol Abuse 41, 479-488. doi: 10.3109/00952990.2015.1058812

Kendall, C. E., Wong, J., Taljaard, M., Glazier, R. H., Hogg, W., Younger, J., et al. (2014). A cross-sectional, population-based study measuring comorbidity among people living with HIV in Ontario. BMC Public Health 14:161. doi: 10.1186/1471-2458-14-161

Kieburtz, K., Ketonen, L., Cox, C., Grossman, H., Holloway, R., Booth, H., et al. (1996). Cognitive performance and regional brain volume in human immunodeficiency virus type 1 infection. Arch. Neurol. 53, 155-158. doi: 10.1001/archneur.1996.00550020059016

Kim, A. Y., and Chung, R. T. (2009). Coinfection with HIV-1 and HCV-a one-two punch. Gastroenterology 137, 795-814. doi: 10.1053/j.gastro.2009.06.040

Kim, D. J., Park, B., and Park, H. J. (2013). Functional connectivity-based identification of subdivisions of the basal ganglia and thalamus using multilevel independent component analysis of resting state fMRI. Hum. Brain Mapp. 34, 1371-1385. doi: 10.1002/hbm.21517

Kranick, S. M., and Nath, A. (2012). Neurologic complications of HIV-1 infection and its treatment in the era of antiretroviral therapy. Continuum 18, 1319-1337. doi: 10.1212/01.CON.0000423849.24900.ec

Kuhn, T., Sayegh, P., Jones, J. D., Smith, J., Sarma, M. K., Ragin, A., et al. (2017). Improvements in brain and behavior following eradication of hepatitis C. J. Neurovirol. 23, 593-602. doi: 10.1007/s13365-017-0533-0

Lake, J. E., Popov, M., Post, W. S., Palella, F. J., Sacktor, N., Miller, E. N., et al. (2017). Visceral fat is associated with brain structure independent of human immunodeficiency virus infection status. J. Neurovirol. 23, 385-393. doi: 10.1007/s13365-016-0507-7

Lane, T. A., Moore, D. M., Batchelor, J., Brew, B. J., and Cysique, L. A. (2012). Facial emotional processing in HIV infection: relation to neurocognitive and neuropsychiatric status. Neuropsychology 26, 713-722. doi: 10.1037/ a0029964

Le Berre, A. P., Fama, R., and Sullivan, E. V. (2017). Executive functions, memory, and social cognitive deficits and recovery in chronic alcoholism: a critical review to inform future research. Alcohol. Clin. Exp. Res. 41, 1432-1443. doi: 10.1111/acer.13431

Leite, S. C., Correa, D. G., Doring, T. M., Kubo, T. T., Netto, T. M., Ferracini, R., et al. (2013). Diffusion tensor MRI evaluation of the corona radiata, cingulate gyri, and corpus callosum in HIV patients. J. Magn. Reson. Imaging 38, 1488-1493. doi: 10.1002/jmri.24129

Lentz, M. R., Kim, W. K., Kim, H., Soulas, C., Lee, V., Venna, N., et al. (2011). Alterations in brain metabolism during the first year of HIV infection. J. Neurovirol. 17, 220-229. doi: 10.1007/s13365-011-0030-9

Leserman, J. (2008). Role of depression, stress, and trauma in HIV disease progression. Psychosom. Med. 70, 539-545. doi: 10.1097/PSY.0b013e3181777a5f 
Letendre, S. L., Cherner, M., Ellis, R. J., Marquie-Beck, J., Gragg, B., Marcotte, T., et al. (2005). The effects of hepatitis C, HIV, and methamphetamine dependence on neuropsychological performance: biological correlates of disease. AIDS 19(Suppl. 3), S72-S78. doi: 10.1097/01.aids.0000192073.18691.ff

Li, S., Wu, Y., Keating, S. M., Du, H., Sammet, C. L., Zadikoff, C., et al. (2013). Matrix metalloproteinase levels in early HIV infection and relation to in vivo brain status. J. Neurovirol. 19, 452-460. doi: 10.1007/s13365-013-0197-3

Li, Y., Li, H., Gao, Q., Yuan, D., and Zhao, J. (2014). Structural gray matter change early in male patients with HIV. Int. J. Clin. Exp. Med. 7, 3362-3369.

Lindau, S. T., Schumm, L. P., Laumann, E. O., Levinson, W., O’Muircheartaigh, C. A., and Waite, L. J. (2007). A study of sexuality and health among older adults in the United States. N. Engl. J. Med. 357, 762-774. doi: 10.1056/NEJMoa0 67423

López-Villegas, D., Lenkinski, R. E., and Frank, I. (1997). Biochemical changes in the frontal lobe of HIV-infected individuals detected by magnetic resonance spectroscopy. Proc. Natl. Acad. Sci. U.S.A. 94, 9854-9859. doi: 10.1073/pnas.94.18.9854

Luetkemeyer, A., Hare, C. B., Stansell, J., Tien, P. C., Charlesbois, E., Lum, P., et al. (2006). Clinical presentation and course of acute hepatitis C infection in HIV-infected patients. J. Acquir. Immune Defic. Syndr. 41, 31-36. doi: 10.1097/01.qai.0000191281.77954.27

Ma, Q., Vaida, F., Wong, J., Sanders, C. A., Kao, Y. T., Croteau, D., et al. (2016). Long-term efavirenz use is associated with worse neurocognitive functioning in HIV-infected patients. J. Neurovirol. 22, 170-178. doi: $10.1007 / \mathrm{s} 13365-015-0382-7$

Maj, M., Satz, P., Janssen, R., Zaudig, M., Starace, F., D’Elia, L., et al. (1994)., WHO Neuropsychiatric AIDS study, cross-sectional phase INeuropsychological, I., and neurological findings. Arch. Gen. Psychiatry 51, 51-61. doi: 10.1001/archpsyc. 1994.03950010051007

Maniega, S. M., Valdes Hernandez, M. C., Clayden, J. D., Royle, N. A., Murray, C., Morris, Z., et al. (2015). White matter hyperintensities and normal-appearing white matter integrity in the aging brain. Neurobiol. Aging 36, 909-918. doi: 10.1016/j.neurobiolaging.2014.07.048

Manji, H., Jager, H. R., and Winston, A. (2013). HIV, dementia and antiretroviral drugs: 30 years of an epidemic. J. Neurol. Neurosurg. Psychiatr. 84, 1126-1137. doi: 10.1136/jnnp-2012-304022

Marcotte, T. D., Lazzaretto, D., Scott, J. C., Roberts, E., Woods, S. P., and Letendre, S. (2006). Visual attention deficits are associated with driving accidents in cognitively-impaired HIV-infected individuals. J. Clin. Exp. Neuropsychol. 28, 13-28. doi: 10.1080/13803390490918048

Marder, K., Albert, S. M., McDermott, M. P., McArthur, J. C., Schifitto, G., Selnes, O. A., et al. (2003). Inter-rater reliability of a clinical staging of HIV-associated cognitive impairment. Neurology 60, 1467-1473. doi: 10.1212/01.WNL.0000064172.46685.82

Martin, E. M., Pitrak, D. L., Rains, N., Grbesic, S., Pursell, K., Nunnally, G., et al. (2003). Delayed nonmatch-to-sample performance in HIV-seropositive and HIV-seronegative polydrug abusers. Neuropsychology 17, 283-288. doi: 10.1037/0894-4105.17.2.283

Martin, E., Gonzalez, R., Vassileva, J., and Bechara, A. (2015). Delay discounting is greater among drug users seropositive for hepatitis C but not HIV. Neuropsychology 29, 926-932. doi: 10.1037/neu0000207

Martin-Thormeyer, E. M., and Paul, R. H. (2009). Drug abuse and hepatitis C infection as comorbid features of HIV associated neurocognitive disorder: neurocognitive and neuroimaging features. Neuropsychol. Rev. 19, 215-231. doi: 10.1007/s11065-009-9101-6

Mathew, S., Faheem, M., Ibrahim, S. M., Iqbal, W., Rauff, B., Fatima, K., et al. (2016). Hepatitis C virus and neurological damage. World J. Hepatol. 8, 545-556. doi: 10.4254/wjh.v8.i12.545

McAndrews, M. P., Farcnik, K., Carlen, P., Damyanovich, A., Mrkonjic, M., Jones, S., et al. (2005). Prevalence and significance of neurocognitive dysfunction in hepatitis $\mathrm{C}$ in the absence of correlated risk factors. Hepatology 41, 801-808. doi: $10.1002 /$ hep. 20635

McGinnis, K. A., Fultz, S. L., Skanderson, M., Conigliaro, J., Bryant, K., and Justice, A. C. (2006). Hepatocellular carcinoma and non-Hodgkin's lymphoma: the roles of HIV, hepatitis C infection, and alcohol abuse. J. Clin. Oncol. 24, 5005-5009. doi: 10.1200/JCO.2006.05.7984

McMurtray, A., Nakamoto, B., Shikuma, C., and Valcour, V. (2008). Cortical atrophy and white matter hyperintensities in HIV: the hawaii aging with HIV cohort study. J. Stroke Cerebrovasc. Dis. 17, 212-217. doi: 10.1016/j.jstrokecerebrovasdis.2008.02.005

McNamara, P. H., Coen, R., Redmond, J., Doherty, C. P., and Bergin, C. (2017). A High Prevalence Rate of a Positive Screen for Cognitive Impairment in Patients With Human Immunodeficiency Virus Attending an Irish Clinic. Open Forum Infect. Dis. 4:ofw242. doi: 10.1093/ofid/ofw242

Metzler-Baddeley, C., O'Sullivan, M. J., Bells, S., Pasternak, O., and Jones, D. K. (2012). How and how not to correct for CSF-contamination in diffusion MRI. Neuroimage 59, 1394-1403. doi: 10.1016/j.neuroimage.2011. 08.043

Meyerhoff, D. J., Blumenfeld, R., Truran, D., Lindgren, J., Flenniken, D., Cardenas, V., et al. (2004). Effects of heavy drinking, binge drinking, and family history of alcoholism on regional brain metabolites. Alcohol. Clin. Exp. Res. 28, 650-661. doi: 10.1097/01.ALC.0000121805.12350.CA

Miguez, M. J., Shor-Posner, G., Morales, G., Rodriguez, A., and Burbano, X. (2003). HIV treatment in drug abusers: impact of alcohol use. Addict. Biol. 8, 33-37. doi: $10.1080 / 1355621031000069855$

Míguez-Burbano, M. J., Espinoza, L., Whitehead, N. E., Bryant, V. E., Vargas, M., Cook, R. L., et al. (2014). Brain derived neurotrophic factor and cognitive status: the delicate balance among people living with HIV, with and without alcohol abuse. Curr. HIV Res. 12, 254-264. doi: 10.2174/1570162X12666140721121238

Miller, B. L. (1991). A review of chemical issues in 1H NMR spectroscopy: $\mathrm{N}$-acetyl-L-aspartate, creatine and choline. NMR Biomed. 4, 47-52. doi: $10.1002 / \mathrm{nbm} .1940040203$

Modi, S., Bhattacharya, M., Kumar, P., Deshpande, S. N., Tripathi, R. P., and Khushu, S. (2011). Brain metabolite changes in alcoholism: localized proton magnetic resonance spectroscopy study of the occipital lobe. Eur. J. Radiol. 79, 96-100. doi: 10.1016/j.ejrad.2009.11.003

Molsberry, S. A., Lecci, F., Kingsley, L., Junker, B., Reynolds, S., Goodkin, K., et al. (2015). Mixed membership trajectory models of cognitive impairment in the multicenter AIDS cohort study. AIDS 29, 713-721. doi: 10.1097/QAD.0000000000000561

Moore, R. D., and Chaisson, R. E. (1999). Natural history of HIV infection in the era of combination antiretroviral therapy. AIDS 13, 1933-1942. doi: 10.1097/00002030-199910010-00017

Morgan, E. E., Woods, S. P., Delano-Wood, L., Bondi, M. W., Grant, I., and Group HIVNRP. (2011). Intraindividual variability in HIV infection: evidence for greater neurocognitive dispersion in older HIV seropositive adults. Neuropsychology 25, 645-654. doi: 10.1037/a0 023792

Müller-Oehring, E. M., Schulte, T., Fama, R., Pfefferbaum, A., and Sullivan, E. V. (2009). Global-local interference is related to callosal compromise in alcoholism: a behavior-DTI association study. Alcohol. Clin. Exp. Res. 33, 477-489. doi: 10.1111/j.1530-0277.2008.00858.x

Myhre, J., and Sifris, D. (2017). When Did HAART Become ART? Change Is About More Than Just Semantics. Available online at: http://www.verywell.com

Nakamoto, B. K., Jahanshad, N., McMurtray, A., Kallianpur, K. J., Chow, D. C., Valcour, V. G., et al. (2012). Cerebrovascular risk factors and brain microstructural abnormalities on diffusion tensor images in HIV-infected individuals. J. Neurovirol. 18, 303-312. doi: 10.1007/s13365-012-0106-1

Nakazato, A., Tominaga, D., Tasato, D., Miyagi, K., Nakamura, H., Haranaga, S., et al. (2014). Are MMSE and HDS-R neuropsychological tests adequate for screening HIV-associated neurocognitive disorders? J. Infect. Chemother. 20, 217-219. doi: 10.1016/j.jiac.2013.10.005

Narvid, J., Rehani, B., and Talbott, J. F. (2016). Diagnostic performance of brain MRI in immune reconstitution inflammatory syndrome. J. Neuroimaging 26, 303-308. doi: 10.1111/jon.12291

Nasi, M., De Biasi, S., Gibellini, L., Bianchini, E., Pecorini, S., Bacca, V., et al. (2017). Ageing and inflammation in patients with HIV infection. Clin. Exp. Immunol. 187, 44-52. doi: $10.1111 /$ cei. 12814

Nasi, M., Pinti, M., Mussini, C., and Cossarizza, A. (2014). Persistent inflammation in HIV infection: established concepts, new perspectives. Immunol. Lett. 161, 184-188. doi: 10.1016/j.imlet.2014.01.008

Newton, H. B. (1995). Common neurologic complications of HIV-1 infection and AIDS. Am. Fam. Physician 51, 387-398.

Nir, T. M., Jahanshad, N., Busovaca, E., Wendelken, L., Nicolas, K., Thompson, P. M., et al. (2014). Mapping white matter integrity in elderly people with HIV. Hum. Brain Mapp. 35, 975-992. doi: 10.1002/hbm.22228 
Nishijima, T., Gatanaga, H., Teruya, K., Tajima, T., Kikuchi, Y., Hasuo, K., et al. (2014). Brain magnetic resonance imaging screening is not useful for HIV-1infected patients without neurological symptoms. AIDS Res. Hum. Retroviruses 30, 970-974. doi: 10.1089/aid.2014.0123

Noble, J. M., and Weimer, L. H. (2014). Neurologic complications of alcoholism. Continuum 20, 624-641. doi: 10.1212/01.CON.0000450970.99322.84

Ojaimi, S., Lin, M. W., Singh, K. P., and Woolley, I. (2014). The two-edged sword: vasculitis associated with HIV and hepatitis C coinfection. Int. J. STD AIDS 25, 77-88. doi: 10.1177/0956462413495671

Önen, N. F., and Overton, E. T. (2011). A review of premature frailty in HIVinfected persons; another manifestation of HIV-related accelerated aging. Curr. Aging Sci. 4, 33-41. doi: 10.2174/1874609811104010033

Ortega, M., Baker, L. M., Vaida, F., Paul, R., Basco, B., and Ances, B. M. (2015). Physical Activity Affects Brain Integrity in HIV+ Individuals. J. Int. Neuropsychol. Soc. 21, 880-889. doi: 10.1017/S1355617715000879

Oscar-Berman, M., Valmas, M. M., Sawyer, K. S., Ruiz, S. M., Luhar, R. B., and Gravitz, Z. R. (2014). Profiles of impaired, spared, and recovered neuropsychologic processes in alcoholism. Handb. Clin. Neurol. 125, 183-210. doi: 10.1016/B978-0-444-62619-6.00012-4

Parks, M. H., Dawant, B. M., Riddle, W. R., Hartmann, S. L., Dietrich, M. S., Nickel, M. K., et al. (2002). Longitudinal brain metabolic characterization of chronic alcoholics with proton magnetic resonance spectroscopy. Alcohol. Clin. Exp. Res. 26, 1368-1380. doi: 10.1111/j.1530-0277.2002.tb02681.x

Parsons, T. D., Tucker, K. A., Hall, C. D., Robertson, W. T., Eron, J. J., Fried, M. W., et al. (2006). Neurocognitive functioning and HAART in HIV and hepatitis C virus co-infection. AIDS 20, 1591-1595. doi: 10.1097/01.aids.0000238404.16121.47

Pasternak, O., Shenton, M. E., and Westin, C. F. (2012). Estimation of extracellular volume from regularized multi-shell diffusion MRI. Med. Image Comput. Comput. Assist. Interv. 15, 305-312. doi: 10.1007/978-3-642-33418-4_38

Pasternak, O., Sochen, N., Gur, Y., Intrator, N., and Assaf, Y. (2009). Free water elimination and mapping from diffusion MRI. Magn. Reson. Med. 62, 717-730. doi: $10.1002 / \mathrm{mrm} .22055$

Paul, R. H., Ernst, T., Brickman, A. M., Yiannoutsos, C. T., Tate, D. F., Cohen, R. A., et al. (2008). Relative sensitivity of magnetic resonance spectroscopy and quantitative magnetic resonance imaging to cognitive function among nondemented individuals infected with HIV. J. Int. Neuropsychol. Soc. 14, 725-733. doi: 10.1017/S1355617708080910

Paul, R., Cohen, R., Navia, B., and Tashima, K. (2002). Relationships between cognition and structural neuroimaging findings in adults with human immunodeficiency virus type-1. Neurosci. Biobehav. Rev. 26, 353-359. doi: 10.1016/S0149-7634(02)00006-4

Pence, B. W., Thielman, N. M., Whetten, K., Ostermann, J., Kumar, V., and Mugavero, M. J. (2008). Coping strategies and patterns of alcohol and drug use among HIV-infected patients in the United States Southeast. AIDS Patient Care STDS 22, 869-877. doi: 10.1089/apc.2008.0022

Peng, J., Lu, F., Wang, Z., Zhong, M., Sun, L., Hu, N., et al. (2014). Excessive lowering of blood pressure is not beneficial for progression of brain white matter hyperintensive and cognitive impairment in elderly hypertensive patients: 4-year follow-up study. J. Am. Med. Dir. Assoc. 15, 904-910. doi: 10.1016/j.jamda.2014.07.005

Perry, W., Carlson, M. D., Barakat, F., Hilsabeck, R. C., Schiehser, D. M., Mathews, C., et al. (2005). Neuropsychological test performance in patients co-infected with hepatitis C virus and HIV. AIDS 19(Suppl. 3), S79-S84. doi: 10.1097/01.aids.0000192074.18691.31

Petry, N. M. (1999). Alcohol use in, HIV and patients: what we don't know may hurt us. Int. J. STDAIDS 10, 561-570. doi: 10.1258/0956462991914654

Pfefferbaum, A., Adalsteinsson, E., and Sullivan, E. V. (2005). Cortical NAA Deficits in HIV infection without dementia: influence of alcoholism comorbidity. Neuropsychopharmacology 30, 1392-1399. doi: 10.1038/sj.npp.1300723

Pfefferbaum, A., Adalsteinsson, E., and Sullivan, E. V. (2006). Supratentorial profile of white matter microstructural integrity in recovering alcoholic men and women. Biol. Psychiatry 59, 364-372. doi: 10.1016/j.biopsych.2005. 06.025

Pfefferbaum, A., and Sullivan, E. V. (2002). Microstructural but not macrostructural disruption of white matter in women with chronic alcoholism. Neuroimage 15, 708-718. doi: 10.1006/nimg.2001.1018
Pfefferbaum, A., and Sullivan, E. V. (2005). Disruption of brain white matter microstructure by excessive intracellular and extracellular fluid in alcoholism:, Evidence from diffusion tensor imaging. Neuropsychopharmacology 30, 423-432. doi: 10.1038/sj.npp.1300623

Pfefferbaum, A., Rogosa, D. A., Rosenbloom, M. J., Chu, W., Sassoon, S. A., Kemper, C. A., et al. (2014). Accelerated aging of selective brain structures in human immunodeficiency virus infection: a controlled, longitudinal magnetic resonance imaging study. Neurobiol. Aging 35, 1755-1768. doi: 10.1016/j.neurobiolaging.2014.01.008

Pfefferbaum, A., Rosenbloom, M. J., Adalsteinsson, E., and Sullivan, E. V. (2007). Diffusion tensor imaging with quantitative fiber tracking in HIV infection and alcoholism comorbidity: synergistic white matter damage. Brain 130, 48-64. doi: 10.1093/brain/awl242

Pfefferbaum, A., Rosenbloom, M. J., Rohlfing, T., Kemper, C. A., Deresinski, S., and Sullivan, E. V. (2009a). Frontostriatal fiber bundle compromise in HIV infection without dementia. AIDS 23, 1977-1985. doi: 10.1097/QAD.0b013e32832e77fe

Pfefferbaum, A., Rosenbloom, M. J., Sassoon, S. A., Kemper, C. A., Deresinski, S., Rohlfing, T., et al. (2012). Regional brain structural dysmorphology in human immunodeficiency virus infection: effects of acquired immune deficiency syndrome, alcoholism, and age. Biol. Psychiatry 72, 361-370. doi: $10.1016 /$ j.biopsych.2012.02.018

Pfefferbaum, A., Rosenbloom, M. J., Serventi, K., and Sullivan, E. V. (2002a). Corpus callosum, pons and cortical white matter in alcoholic women. Alcohol. Clin. Exp. Res. 26, 400-405. doi: 10.1111/j.1530-0277.2002.tb02552.x

Pfefferbaum, A., Rosenbloom, M., and Sullivan, E. V. (2002b). Alcoholism and AIDS: magnetic resonance imaging approaches for detecting interactive neuropathology. Alcohol. Clin. Exp. Res. 26, 1031-1046. doi: 10.1111/j.1530-0277.2002.tb02638.x

Pfefferbaum, A., Rosenbloom, M., Rohlfing, T., and Sullivan, E. V. (2009b). Degradation of association and projection white matter systems in alcoholism detected with quantitative fiber tracking. Biol. Psychiatry 65, 680-690. doi: 10.1016/j.biopsych.2008.10.039

Pfefferbaum, A., Sullivan, E. V., Hedehus, M., Adalsteinsson, E., Lim, K. O., and Moseley, M. (2000). In vivo detection and functional correlates of white matter microstructural disruption in chronic alcoholism. Alcohol. Clin. Exp. Res. 24, 1214-1221. doi: 10.1111/j.1530-0277.2000.tb02086.x

Pfefferbaum, A., Sullivan, E. V., Mathalon, D. H., and Lim, K. O. (1997). Frontal lobe volume loss observed with magnetic resonance imaging in older chronic alcoholics. Alcohol. Clin. Exp. Res. 21, 521-529. doi: 10.1111/j.1530-0277.1997.tb03798.x

Pitel, A. L., Chetelat, G., Le Berre, A. P., Desgranges, B., Eustache, F., and Beaunieux, H. (2012). Macrostructural abnormalities in Korsakoff syndrome compared with uncomplicated alcoholism. Neurology 78, 1330-1333. doi: 10.1212/WNL.0b013e318251834e

Powderly, W. G. (2002). Sorting through confusing messages: the art of HAART. J. Acquir. Immune Defic. Syndr. 31(Suppl. 1), S3-S9; discussion S24-5. doi: 10.1097/00126334-200209011-00002

Prakash, A., Hou, J., Liu, L., Gao, Y., Kettering, C., and Ragin, A. B. (2016). Cognitive function in early HIV infection. J. Neurovirol. 3, 273-282. doi: 10.1007/s13365-016-0498-4

Ragin, A. B., D'Souza, G., Reynolds, S., Miller, E., Sacktor, N., Selnes, O. A., et al. (2011). Platelet decline as a predictor of brain injury in HIV infection. J. Neurovirol. 17, 487-495. doi: 10.1007/s13365-011-0053-2

Ragin, A. B., Du, H., Ochs, R., Wu, Y., Sammet, C. L., Shoukry, A., et al. (2012). Structural brain alterations can be detected early in HIV infection. Neurology 79, 2328-2334. doi: 10.1212/WNL.0b013e318278b5b4

Rahimy, E., Li, F. Y., Hagberg, L., Fuchs, D., Robertson, K., Meyerhoff, D. J., et al. (2017). Blood-brain barrier disruption is initiated during primary HIV infection and not rapidly altered by antiretroviral therapy. J. Infect. Dis. 215, 1132-1140. doi: 10.1093/infdis/jix013

Ramasubbu, R., Taylor, V. H., Samaan, Z., Sockalingham, S., Li, M., Patten, S., et al. (2012). The Canadian Network for Mood and Anxiety Treatments (CANMAT) task force recommendations for the management of patients with mood disorders and select comorbid medical conditions. Ann. Clin. Psychiatry 24, 91-109.

Ramos-Casals, M., Forns, X., Brito-Zeron, P., Vargas, A., Ruiz, M., Laguno, M., et al. (2007). Cryoglobulinaemia associated with hepatitis $C$ virus: influence of 
HCV genotypes, HCV-RNA viraemia and HIV coinfection. J. Viral Hepat. 14, 736-742. doi: 10.1111/j.1365-2893.2007.00866.x

Reichenberg, A., Gorman, J. M., and Dieterich, D. T. (2005). Interferoninduced depression and cognitive impairment in hepatitis $C$ virus patients: a 72 week prospective study. AIDS 19(Suppl. 3), S174-S178. doi: 10.1097/01.aids.0000192087.64432.ae

Richardson, J. L., Nowicki, M., Danley, K., Martin, E. M., Cohen, M. H., Gonzalez, R., et al. (2005). Neuropsychological functioning in a cohort of HIV- and hepatitis C virus-infected women. AIDS 19, 1659-1667. doi: 10.1097/01.aids.0000186824.53359.62

Robertson, K. R., Smurzynski, M., Parsons, T. D., Wu, K., Bosch, R. J., Wu, J., et al. (2007). The prevalence and incidence of neurocognitive impairment in the HAART era. AIDS 21, 1915-1921. doi: 10.1097/QAD.0b013e328 $28 \mathrm{e} 4 \mathrm{e} 27$

Robertson, K., Kumwenda, J., Supparatpinyo, K., Jiang, J. H., Evans, S., Campbell, T. B., et al. (2011). A multinational study of neurological performance in antiretroviral therapy-naive HIV-1-infected persons in diverse resource-constrained settings. J. Neurovirol. 17, 438-447. doi: 10.1007/s13365-011-0044-3

Robertson, K., Liner, J., and Heaton, R. (2009). Neuropsychological assessment of HIV-infected populations in international settings. Neuropsychol. Rev. 19, 232-249. doi: 10.1007/s11065-009-9096-z

Robinson-Papp, J., Navis, A., Dhamoon, M. S., Clark, U. S., Gutierrez-Contreras, J., and Morgello, S. (2017). The use of visual rating scales to quantify brain MRI lesions in patients with HIV infection. J. Neuroimaging. doi: 10.1111/jon.12466. [Epub ahead of print].

Romão, P. R., Lemos, J. C., Moreira, J., de Chaves, G., Moretti, M., Castro, A. A., et al. (2011). Anti-HIV drugs nevirapine and efavirenz affect anxietyrelated behavior and cognitive performance in mice. Neurotox. Res. 19, 73-80. doi: 10.1007/s12640-009-9141-y

Rosenbloom, M. J., Sullivan, E. V., Sassoon, S. A., O’Reilly, A., Fama, R., Kemper, C. A., et al. (2007). Alcoholism, HIV infection and their comorbidity: factors affecting self-rated health-related quality of life. J. Stud. Alcohol Drugs 68, 115-125. doi: $10.15288 /$ issad.2007.68.115

Rosenbloom, M., Sullivan, E. V., and Pfefferbaum, A. (2010). Focus on the brain: HIV infection and alcoholism: comorbidity effects on brain structure and function. Alcohol Res. Health 33, 247-257.

Rostrup, E., Gouw, A. A., Vrenken, H., van Straaten, E. C., Ropele, S., Pantoni, L., et al. (2012). The spatial distribution of age-related white matter changes as a function of vascular risk factors-results from the LADIS study. Neuroimage 60, 1597-1607. doi: 10.1016/j.neuroimage.2012.01.106

Rothlind, J. C., Greenfield, T. M., Bruce, A. V., Meyerhoff, D. J., Flenniken, D. L., Lindgren, J. A., et al. (2005). Heavy alcohol consumption in individuals with HIV infection: effects on neuropsychological performance. J. Int. Neuropsychol. Soc. 11, 70-83. doi: 10.1017/S1355617705050095

Rubin, L. H., Meyer, V. J., J Conant R., Sundermann, E. E., Wu, M., Weber, K. M., et al. (2016). Prefrontal cortical volume loss is associated with stress-related deficits in verbal learning and memory in HIV-infected women. Neurobiol. Dis. 92, 166-174. doi: 10.1016/j.nbd.2015.09.010

Ryan, E. L., Morgello, S., Isaacs, K., Naseer, M., Gerits, P., and Manhattan HIVBB. (2004). Neuropsychiatric impact of hepatitis C on advanced HIV. Neurology 62, 957-962. doi: 10.1212/01.WNL.0000115177.74976.6C

Sacktor, N., Skolasky, R. L., Seaberg, E., Munro, C., Becker, J. T., Martin, E., et al. (2016). Prevalence of HIV-associated neurocognitive disorders in the Multicenter AIDS Cohort Study. Neurology 86, 334-340. doi: 10.1212/WNL.0000000000002277

Sailasuta, N., Ross, W., Ananworanich, J., Chalermchai, T., DeGruttola, V., Lerdlum, S., et al. (2012). Change in brain magnetic resonance spectroscopy after treatment during acute HIV infection. PLoS ONE 7:e49272. doi: 10.1371/journal.pone.0049272

Samet, J. H., Phillips, S. J., Horton, N. J., Traphagen, E. T., and Freedberg, K. A. (2004). Detecting alcohol problems in HIV-infected patients: use of the CAGE questionnaire. AIDS Res. Hum. Retroviruses 20, 151-155. doi: $10.1089 / 088922204773004860$

Samet, J. H., Walley, A. Y., and Bridden, C. (2007). Illicit drugs, alcohol, and addiction in human immunodeficiency virus. Panminerva Med. 49, 67-77.

Sanford, R., Fernandez Cruz, A. L., Scott, S. C., Mayo, N. E., Fellows, L. K., Ances, B. M., et al. (2017). Regionally specific brain volumetric and cortical thickness changes in HIV-infected patients in the HAART Era. J. Acquir. Immune Defic. Syndr. 74, 563-570. doi: 10.1097/QAI.0000000000001294

Sassoon, S. A., Fama, R., Rosenbloom, M. J., O’Reilly, A., Pfefferbaum, A., and Sullivan, E. V. (2007). Component cognitive and motor processes of the digit symbol test: differential deficits in alcoholism, HIV infection and their comorbidity. Alcohol. Clin. Exp. Res. 31, 1315-1324. doi: 10.1111/j.1530-0277.2007.00426.x

Sassoon, S. A., Rosenbloom, M. J., Fama, R., Sullivan, E. V., and Pfefferbaum, A. (2012). Selective neurocognitive deficits and poor life functioning are associated with significant depressive symptoms in alcoholism-HIV infection comorbidity. Psychiatry Res. 199, 102-110. doi: 10.1016/j.psychres.2012.05.009

Saylor, D., Nakigozi, G., Nakasujja, N., Robertson, K., Gray, R. H., Wawer, M. J., et al. (2017). Peripheral neuropathy in HIV-infected and uninfected patients in Rakai, Uganda. Neurology 9, 485-491. doi: 10.1212/WNL.00000000000 04136

Schretlen, D. J., Munro, C. A., Anthony, J. C., and Pearlson, G. D. (2003). Examining the range of normal intraindividual variability in neuropsychological test performance. J. Int. Neuropsychol. Soc. 9, 864-870. doi: $10.1017 /$ S1355617703960061

Schuitemaker, A. van der Doef, T. F., Boellaard, R., van der Flier, W. M., Yaqub, M., Windhorst, A. D., et al. (2012). Microglial activation in healthy aging. Neurobiol. Aging 33, 1067-1072. doi: 10.1016/j.neurobiolaging.2010. 09.016

Schulte, T., Müller-Oehring, E. M., Rosenbloom, M. J., Pfefferbaum, A., and Sullivan, E. V. (2005). Differential effect of HIV infection and alcoholism on conflict processing, attentional allocation, and perceptual load: evidence from a Stroop Match-to-Sample task. Biol. Psychiatry 57, 67-75. doi: 10.1016/j.biopsych.2004.09.025

Schulte, T., Müller-Oehring, E. M., Sullivan, E. V., and Pfefferbaum, A. (2012). White matter fiber compromise contributes differentially to attention and emotion processing impairment in alcoholism, HIVinfection, and their comorbidity. Neuropsychologia 50, 2812-2822. doi: 10.1016/j.neuropsychologia.2012.07.042

Schweinsburg, B. C., Alhassoon, O. M., Taylor, M. J., Gonzalez, R., Videen, J. S., Brown, G. G., et al. (2003). Effects of alcoholism and gender on brain metabolism. Am. J. Psychiatry 160, 1180-1183. doi: 10.1176/appi.ajp.160.6.1180

Scott, J., Underwood, J., Garvey, L. J., Mora-Peris, B., and Winston, A. (2016). A comparison of two post-processing analysis methods to quantify cerebral metabolites measured via proton magnetic resonance spectroscopy in HIV disease. Br. J. Radiol. 89:20150979. doi: 10.1259/bir.20150979

Seider, T. R., Gongvatana, A., Woods, A. J., Chen, H., Porges, E. C., Cummings, T., et al. (2016). Age exacerbates HIV-associated white matter abnormalities. J. Neurovirol. 22, 201-212. doi: 10.1007/s13365-015-0386-3

Seitz, D., Widmann, U., Seeger, U., Nagele, T., Klose, U., Mann, K., et al. (1999). Localized proton magnetic resonance spectroscopy of the cerebellum in detoxifying alcoholics. Alcohol. Clin. Exp. Res. 23, 158-163. doi: 10.1111/j.1530-0277.1999.tb04038.x

Shear, P. K., Sullivan, E. V., Lane, B., and Pfefferbaum, A. (1996). Mammillary body and cerebellar shrinkage in chronic alcoholics with and without amnesia. Alcohol. Clin. Exp. Res. 20, 1489-1495. doi: 10.1111/j.1530-0277.1996.tb01 153.x

Sheppard, D. P., Iudicello, J. E., Bondi, M. W., Doyle, K. L., Morgan, E. E., Massman, P. J., et al. (2015). Elevated rates of mild cognitive impairment in HIV disease. J. Neurovirol. 21, 576-584. doi: 10.1007/s13365-015-0366-7

Shin, N. Y., Hong, J., Choi, J. Y., Lee, S. K., Lim, S. M., and Yoon, U. (2017). Retrosplenial cortical thinning as a possible major contributor for cognitive impairment in HIV patients. Eur. Radiol. 27, 4721-4729. doi: 10.1007/s00330-017-4836-6

Shoamanesh, A., Preis, S. R., Beiser, A. S., Vasan, R. S., Benjamin, E. J., Kase, C. S., et al. (2015). Inflammatory biomarkers, cerebral microbleeds, and small vessel disease: framingham heart study. Neurology 84, 825-832. doi: 10.1212/WNL.0000000000001279

Simet, S. M., and Sisson, J. H. (2015). Alcohol's effects on lung health and immunity. Alcohol Res. 37, 199-208.

Soboka, M., Tesfaye, M., Feyissa, G. T., and Hanlon, C. (2014). Alcohol use disorders and associated factors among people living with HIV who are attending services in south west Ethiopia. BMC Res. Notes 7:828. doi: $10.1186 / 1756-0500-7-828$ 
Soogoor, M., Lynn, H. S., Donfield, S. M., Gomperts, E., Bell, T. S., Daar, E. S., et al. (2006). Hepatitis C virus infection and neurocognitive function. Neurology 67, 1482-1485. doi: 10.1212/01.wnl.0000240255.42608.99

Soriano, V., Vispo, E., Labarga, P., Medrano, J., and Barreiro, P. (2010). Viral hepatitis and HIV co-infection. Antiviral Res. 85, 303-315. doi: 10.1016/j.antiviral.2009.10.021

Šprah, L., Dernovsek, M. Z., Wahlbeck, K., and Haaramo, P. (2017). Psychiatric readmissions and their association with physical comorbidity: a systematic literature review. BMC Psychiatry 17:2. doi: 10.1186/s12888-016$1172-3$

Spudich, S. S., and Ances, B. M. (2012). Neurologic complications of HIV infection. Top. Antiviral Med. 20, 41-47.

Stebbins, G. T., Smith, C. A., Bartt, R. E., Kessler, H. A., Adeyemi, O. M., Martin, E., et al. (2007). HIV-associated alterations in normal-appearing white matter: a voxel-wise diffusion tensor imaging study. J Acquir Immune Defic Syndr. 46, 564-573. doi: 10.1097/QAI.0b013e318159d807

Steinbrink, F., Evers, S., Buerke, B., Young, P., Arendt, G., Koutsilieri, E., et al. (2013). Cognitive impairment in HIV infection is associated with MRI and CSF pattern of neurodegeneration. Eur. J. Neurol. 20, 420-428. doi: 10.1111/ene.12006

Stout, J. C., Ellis, R. J., Jernigan, T. L., Archibald, S. L., Abramson, I., Wolfson, T., et al. (1998). Progressive cerebral volume loss in human immunodeficiency virus infection: a longitudinal volumetric magnetic resonance imaging study. HIV Neurobehavioral Research Center Group. Arch. Neurol. 55, 161-168. doi: 10.1001/archneur.55.2.161

Strain, J. F., Burdo, T. H., Song, S. K., Sun, P., El-Ghazzawy, O., Nelson, B., et al. (2017). Diffusion Basis Spectral Imaging Detects Ongoing Brain Inflammation in Virologically Well Controlled HIV+ Patients. J. Acquir. Immune Defic. Syndr. 76, 423-430. doi: 10.1097/QAI.00000000000 01513

Stubbe-Drger, B., Deppe, M., Mohammadi, S., Keller, S. S., Kugel, H., Gregor, N., et al. (2012). Early microstructural white matter changes in patients with HIV: a diffusion tensor imaging study. BMC Neurol. 12:23. doi: 10.1186/1471-2377-12-23

Su, T., Wit, F. W., Caan, M. W., Schouten, J., Prins, M., Geurtsen, G. J., et al. (2016). White matter hyperintensities in relation to cognition in HIV-infected men with sustained suppressed viral load on combination antiretroviral therapy. AIDS 30, 2329-2339. doi: 10.1097/QAD.00000000000 01133

Sullivan, E. V. (2003). Compromised pontocerebellar and cerebellothalamocortical systems: speculations on their contributions to cognitive and motor impairment in nonamnesic alcoholism. Alcohol. Clin. Exp. Res. 27, 1409-1419. doi: 10.1097/01.ALC.0000085586.91726.46

Sullivan, E. V., Deshmukh, A., De Rosa, E., Rosenbloom, M. J., and Pfefferbaum, A. (2005). Striatal and forebrain nuclei volumes: contribution to motor function and working memory deficits in alcoholism. Biol. Psychiatry 57, 768-776. doi: 10.1016/j.biopsych.2004.12.012

Sullivan, E. V., Deshmukh, A., Desmond, J. E., Lim, K. O., and Pfefferbaum, A. (2000a). Cerebellar volume decline in normal aging, alcoholism, and Korsakoff's syndrome: relation to ataxia. Neuropsychology 14, 341-352. doi: 10.1037/0894-4105.14.3.341

Sullivan, E. V., Fama, R., Rosenbloom, M. J., and Pfefferbaum, A. (2002). A profile of neuropsychological deficits in alcoholic women. Neuropsychology 16, 74-83. doi: 10.1037/0894-4105.16.1.74

Sullivan, E. V., Harding, A. J., Pentney, R., Dlugos, C., Martin, P. R., Parks, M. H., et al. (2003). Disruption of frontocerebellar circuitry and function in alcoholism. Alcohol. Clin. Exp. Res. 27, 301-309. doi: 10.1097/01.ALC.0000052584.05305.98

Sullivan, E. V., Lane, B., Deshmukh, A., Rosenbloom, M. J., Desmond, J. E., Lim, K. O., et al. (1999). In vivo mammillary body volume deficits in amnesic and nonamnesic alcoholics. Alcohol. Clin. Exp. Res. 23, 1629-1636. doi: 10.1111/j.1530-0277.1999.tb04054.x

Sullivan, E. V., Rosenbloom, M. J., and Pfefferbaum, A. (2000c). Pattern of motor and cognitive deficits in detoxified alcoholic men. Alcohol. Clin. Exp. Res. 24, 611-621. doi: 10.1111/j.1530-0277.2000. tb02032.x

Sullivan, E. V., Rosenbloom, M. J., Lim, K. O., and Pfefferbaum, A. (2000b). Longitudinal changes in cognition, gait, and balance in abstinent and relapsed alcoholic men: relationships to changes in brain structure. Neuropsychology 14, 178-188. doi: 10.1037/0894-4105.14.2.178

Sullivan, E. V., Rosenbloom, M. J., Rohlfing, T., Kemper, C. A., Deresinski, S., and Pfefferbaum, A. (2011). Pontocerebellar contribution to ataxia and psychomotor slowing in HIV infection without dementia. Brain Imaging Behav. 5, 12-24. doi: 10.1007/s11682-010-9107-y

Sullivan, L. E., Goulet, J. L., Justice, A. C., and Fiellin, D. A. (2011). Alcohol consumption and depressive symptoms over time: a longitudinal study of patients with and without HIV infection. Drug Alcohol Depend. 117, 158-163. doi: 10.1016/j.drugalcdep.2011.01.014

Sun, B., Abadjian, L., Rempel, H., Monto, A., and Pulliam, L. (2013). Differential cognitive impairment in HCV coinfected men with controlled HIV compared to HCV monoinfection. J. Acquir. Immune Defic. Syndr. 62, 190-196. doi: 10.1097/QAI.0b013e31827b61f1

Tagliati, M., Simpson, D., Morgello, S., Clifford, D., Schwartz, R. L., and Berger, J. R. (1998). Cerebellar degeneration associated with human immunodeficiency virus infection. Neurology 50, 244-251. doi: 10.1212/WNL.50.1.244

Tang, Z., Liu, Z., Li, R., Yang, X., Cui, X., Wang, S., et al. (2017). Identifying the white matter impairments among ART-naive HIV patients: a multivariate pattern analysis of DTI data. Eur. Radiol. 27, 4153-4162. doi: 10.1007/s00330-017-4820-1

Tate, D. F., Delong, A., McCaffrey, D. E., Kertesz, K., Paul, R. H., Conley, J., et al. (2011). Recent clinical history and cognitive dysfunction for attention and executive function among human immunodeficiency virus-infected patients. Arch. Clin. Neuropsychol. 26, 614-623. doi: 10.1093/arclin/acr065

Thaler, N. S., Sayegh, P., Arentoft, A., Thames, A. D., Castellon, S. A., and Hinkin, C. H. (2015). Increased neurocognitive intra-individual variability is associated with declines in medication adherence in HIV-infected adults. Neuropsychology 29, 919-925. doi: 10.1037/neu0000191

Thames, A. D., Castellon, S. A., Singer, E. J., Nagarajan, R., Sarma, M. K., Smith, J., et al. (2015). Neuroimaging abnormalities, neurocognitive function, and fatigue in patients with hepatitis C. Neurol. Neuroimmunol. Neuroinflamm. 2:e59. doi: 10.1212/NXI.0000000000000059

Thames, A. D., Kuhn, T. P., Williamson, T. J., Jones, J. D., Mahmood, Z., and Hammond, A. (2017). Marijuana effects on changes in brain structure and cognitive function among HIV+ and HIV- adults. Drug Alcohol Depend. 170, 120-127. doi: 10.1016/j.drugalcdep.2016.11.007

Thangnipon, W., Taxt, T., Brodal, P., and Storm-Mathisen, J. (1983). The corticopontine projection: axotomy-induced loss of high affinity L-glutamate and $\mathrm{D}$-aspartate uptake, but not of gamma-aminobutyrate uptake, glutamate decarboxylase or choline acetyltransferase, in the pontine nuclei. Neuroscience 8, 449-457. doi: 10.1016/0306-4522(83)90191-4

Thein, H. H., Maruff, P., Krahn, M. D., Kaldor, J. M., Koorey, D. J., Brew, B. J., et al. (2007). Improved cognitive function as a consequence of hepatitis C virus treatment. HIV Med. 8, 520-528. doi: 10.1111/j.1468-1293.2007.00 505.x

Thein, H., Maruff, P., Krahn, M., Kaldor, J., Koorey, D., Brew, B., et al. (2007). Cognitive function, mood and health-related quality of life in hepatitis $C$ virus (HCV)-monoinfected and $\mathrm{HIV} / \mathrm{HCV}$-coinfected individuals commencing HCV treatment. HIV Med. 8, 192-202. doi: 10.1111/j.1468-1293.2007.00 452.x

Thompson, P. M., and Jahanshad, N. (2015). Novel neuroimaging methods to understand How HIV affects the brain. Curr. HIV/AIDS Rep. 12, 289-298. doi: 10.1007/s11904-015-0268-6

Thompson, P. M., Dutton, R. A., Hayashi, K. M., Toga, A. W., Lopez, O. L., Aizenstein, H. J., et al. (2005). Thinning of the cerebral cortex visualized in HIV/AIDS reflects CD4+ T lymphocyte decline. Proc. Natl. Acad. Sci. U.S.A. 102, 15647-15652. doi: 10.1073/pnas.0502548102

Towgood, K. J., Pitkanen, M., Kulasegaram, R., Fradera, A., Kumar, A., Soni, S., et al. (2011). Mapping the brain in younger and older asymptomatic HIV-1 men: frontal volume changes in the absence of other cortical or diffusion tensor abnormalities. Cortex 48, 230-241. doi: 10.1016/j.cortex.2011.03.006

Tran, B. X., Nguyen, L. T., Do, C. D., Nguyen, Q. L., and Maher, R. M. (2014). Associations between alcohol use disorders and adherence to antiretroviral treatment and quality of life amongst people living with HIV/AIDS. BMC Public Health 14:27. doi: 10.1186/1471-2458-14-27

Trivedi, R., Bagga, D., Bhattacharya, D., Kaur, P., Kumar, P., Khushu, S., et al. (2013). White matter damage is associated with memory decline in chronic 
alcoholics: a quantitative diffusion tensor tractography study. Behav. Brain Res. 250, 192-198. doi: 10.1016/j.bbr.2013.05.001

Underwood, J., Cole, J. H., Caan, M., De Francesco, D., Leech, R., van Zoest, R. A., et al. (2017a). Grey and white matter abnormalities in treated HIV-disease and their relationship to cognitive function. Clin. Infect. Dis. 65, 422-432. doi: $10.1093 / \mathrm{cid} / \mathrm{cix} 301$

Underwood, J., De Francesco, D., Post, F. A., Vera, J. H., Williams, I., Boffito, M., et al. (2017b). Pharmacokinetic, and g. Clinical observations in people over fifty study, associations between cognitive impairment and patient-reported measures of physical/mental functioning in older people living with HIV. HIV Med. 18, 363-369. doi: 10.1111/hiv.12434

Valcour, V. G., Shikuma, C. M., Watters, M. R., and Sacktor, N. C. (2004). Cognitive impairment in older HIV-1-seropositive individuals: prevalence and potential mechanisms. AIDS 18(Suppl. 1), S79-S86. doi: 10.1097/00002030-200401001-00012

van Gorp, W. G., Baerwald, J. P., Ferrando, S. J., McElhiney, M. C., and Rabkin, J. G. (1999). The relationship between employment and neuropsychological impairment in HIV infection. J. Int. Neuropsychol. Soc. 5, 534-539. doi: $10.1017 / S 1355617799566071$

van Holst, R. J., de Ruiter, M. B., W., van den Brink, Veltman, D. J., and Goudriaan, A. E. (2012). A voxel-based morphometry study comparing problem gamblers, alcohol abusers, and healthy controls. Drug Alcohol Depend. 124, 142-148. doi: 10.1016/j.drugalcdep.2011.12.025

Vassallo, M., Durant, J., Lebrun-Frenay, C., Fabre, R., Ticchioni, M., Andersen, S., et al. (2015). Virologically suppressed patients with asymptomatic and symptomatic HIV-associated neurocognitive disorders do not display the same pattern of immune activation. HIV Med. 16, 431-440. doi: 10.1111/hiv.12246

Vassar, R. L., and Rose, J. (2014). Motor systems and postural instability. Handb. Clin. Neurol. 125, 237-251. doi: 10.1016/B978-0-444-62619-6.00015-X

Venhoff, N., Lebrecht, D., Deveaud, C., Beauvoit, B., Bonnet, J., Muller, K., et al. (2010). Oral uridine supplementation antagonizes the peripheral neuropathy and encephalopathy induced by antiretroviral nucleoside analogues. AIDS 24 , 345-352. doi: 10.1097/QAD.0b013e328335cdea

Venkataramana, A., Pardo, C. A., McArthur, J. C., Kerr, D. A., Irani, D. N., Griffin, J. W., et al. (2006). Immune reconstitution inflammatory syndrome in the CNS of HIV-infected patients. Neurology 67, 383-388. doi: 10.1212/01.wnl.0000227922.22293.93

Verma, R., and Anand, K. S. (2014). HIV presenting as young-onset dementia. J. Int. Assoc. Provid. AIDS Care 13, 110-112. doi: 10.1177/232595741388173

Vigil, O., Posada, C., Woods, S. P., Atkinson, J. H., Heaton, R. K., Perry, W., et al. (2008). Impairments in fine-motor coordination and speed of information processing predict declines in everyday functioning in hepatitis $\mathrm{C}$ infection. J. Clin. Exp. Neuropsychol. 30, 805-815. doi: 10.1080/13803390701802354

Vigneswaran, S., Rojas, J. H., Garvey, L., Taylor-Robinson, S., and Winston, A. (2015). Differences in the variability of cerebral proton magnetic resonance spectroscopy (1H-MRS) measurements within three HIV-infected cohorts. Neuroradiol. J. 28, 545-554. doi: 10.1177/1971400915609867

Vivithanaporn, P., Heo, G., Gamble, J., Krentz, H. B., Hoke, A., Gill, M. J., et al. (2010). Neurologic disease burden in treated HIV/AIDS predicts survival: a population-based study. Neurology 75, 1150-1158. doi: 10.1212/WNL.0b013e3181f4d5bb

von Giesen, H. J., Heintges, T., Abbasi-Boroudjeni, N., Kucukkoylu, S., Koller, H., Haslinger, B. A., et al. (2004). Psychomotor slowing in hepatitis C and HIV infection. J. Acquir. Immune Defic. Syndr. 35, 131-137. doi: 10.1097/00126334-200402010-00005

Wade, B. S., Valcour, V., Busovaca, E., Esmaeili-Firidouni, P., Joshi, S. H., Wang, Y., et al. (2015). "Subcortical shape and volume abnormalities in an elderly HIV+ cohort," in Proceedings of SPIE-the International Society for Optical Engineering (San Diego, CA), 9417.

Wakabayashi, I. (2014). Frequency of heavy alcohol drinking and risk of metabolic syndrome in middle-aged men. Alcohol. Clin. Exp. Res. 38, 1689-1696. doi: 10.1111 /acer.12425

Wang, B., Liu, Z., Liu, J., Tang, Z., Li, H., and Tian, J. (2016). Gray and white matter alterations in early HIV-infected patients: combined voxel-based morphometry and tract-based spatial statistics. J. Magn. Reson. Imaging 43, 1474-1483. doi: $10.1002 / j m r i .25100$

Watkins, C. C., and Treisman, G. J. (2012). Neuropsychiatric complications of aging with HIV. J. Neurovirol. 18, 277-290. doi: 10.1007/s13365-012-0108-z
Watson, C., Busovaca, E., Foley, J. M., Allen, I. E., Schwarz, C. G., Jahanshad, N., et al. (2017). White matter hyperintensities correlate to cognition and fiber tract integrity in older adults with HIV. J. Neurovirol. 23, 422-429. doi: 10.1007/s13365-016-0509-5

Weber, R., Sabin, C. A., Friis-Moller, N., Reiss, P., El-Sadr, W. M., Kirk, O., et al. (2006). Liver-related deaths in persons infected with the human immunodeficiency virus: the D:A:D study. Arch. Intern. Med. 166, 1632-1641. doi: 10.1001/archinte.166.15.1632

Weissenborn, K., Krause, J., Bokemeyer, M., Hecker, H., Schuler, A., Ennen, J. C., et al. (2004). Hepatitis C virus infection affects the brain-evidence from psychometric studies and magnetic resonance spectroscopy. J. Hepatol. 41, 845-851. doi: 10.1016/j.jhep.2004.07.022

Weissenborn, K., Tryc, A. B., Heeren, M., Worthmann, H., Pflugrad, H., Berding, G., et al. (2009). Hepatitis C virus infection and the brain. Metab. Brain Dis. 24, 197-210. doi: 10.1007/s11011-008-9130-5

Weldegebreal, F., Mitiku, H., and Teklemariam, Z. (2016). Magnitude of adverse drug reaction and associated factors among HIV-infected adults on antiretroviral therapy in Hiwot Fana specialized university hospital, eastern Ethiopia. Pan Afr. Med. J. 24:255. doi: 10.11604/pamj.2016.24. 255.8356

Wendelken, L. A., Jahanshad, N., Rosen, H. J., Busovaca, E., Allen, I., Coppola, G., et al. (2016). ApoE epsilon4 Is Associated With Cognition, Brain Integrity, and Atrophy in HIV Over Age 60. J. Acquir. Immune Defic. Syndr. 73, 426-432. doi: 10.1097/QAI.0000000000001091

Wilcox, C. E., Dekonenko, C. J., Mayer, A. R., Bogenschutz, M. P., and Turner, J. A. (2014). Cognitive control in alcohol use disorder: deficits and clinical relevance. Rev. Neurosci. 25, 1-24. doi: 10.1515/revneuro-2013-0054

Wilson, T. W., Heinrichs-Graham, E., Robertson, K. R., Sandkovsky, U., O'Neill, J., Knott, N. L., et al. (2013). Functional brain abnormalities during finger-tapping in HIV-infected older adults: a magnetoencephalography study. J. Neuroimmune Pharmacol. 8, 965-974. doi: 10.1007/s11481-0139477-1

Woods, S. P., Rippeth, J. D., Frol, A. B., Levy, J. K., Ryan, E., Soukup, V. M., et al. (2004). Interrater reliability of clinical ratings and neurocognitive diagnoses in HIV. J. Clin. Exp. Neuropsychol. 26, 759-778. doi: 10.1080/13803390490509565 Wright, P. W., Pyakurel, A., Vaida, F. F., Price, R. W., Lee, E., Peterson, J., et al. (2016). Putamen volume and its clinical and neurological correlates in primary HIV infection. AIDS 30, 1789-1794. doi: 10.1097/QAD.0000000000001103

Wright, P. W., Vaida, F. F., Fernandez, R. J., Rutlin, J., Price, R. W., Lee, E., et al. (2015). Cerebral white matter integrity during primary HIV infection. AIDS 29, 433-442. doi: 10.1097/QAD.0000000000000560

Xuan, A., Wang, G. B., Shi, D. P., Xu, J. L., and Li, Y. L. (2013). Initial study of magnetic resonance diffusion tensor imaging in brain white matter of early AIDS patients. Chin. Med. J. 126, 2720-2724.

Young, A. C., Yiannoutsos, C. T., Hegde, M., Lee, E., Peterson, J., Walter, R., et al. (2014). Cerebral metabolite changes prior to and after antiretroviral therapy in primary HIV infection. Neurology 83, 1592-1600. doi: 10.1212/WNL.0000000000000932

Zaffiri, L., Verma, R., Struzzieri, K., Monterroso, J., Batts, D. H., and Loehrke, M. E. (2013). Immune reconstitution inflammatory syndrome involving the central nervous system in a patient with HIV infection: a case report and review of literature. New Microbiol. 36, 89-92.

Zahr, N. M., Mayer, D., Rohlfing, T., Hasak, M., Hsu, O., Vinco, S., et al. (2010). Brain injury and recovery following binge ethanol: evidence from in vivo magnetic resonance spectroscopy. Biol. Psychiatry 67, 846-854. doi: 10.1016/j.biopsych.2009.10.028

Zahr, N. M., Mayer, D., Rohlfing, T., Orduna, J., Luong, R., Sullivan, E. V., et al. (2013). A mechanism of rapidly reversible cerebral ventricular enlargement independent of tissue atrophy. Neuropsychopharmacology 38, 1121-1129. doi: 10.1038/npp.2013.11

Zahr, N. M., Mayer, D., Rohlfing, T., Sullivan, E. V., and Pfefferbaum, A. (2014). Imaging neuroinflammation? A perspective from MR spectroscopy. Brain Pathol. 24, 654-664. doi: 10.1111/bpa.12197

Zapata, H. J., and Shaw, A. C. (2014). Aging of the human innate immune system in HIV infection. Curr. Opin. Immunol. 29, 127-136. doi: 10.1016/j.coi.2014.06.007

Zayyad, Z., and Spudich, S. (2015). Neuropathogenesis of HIV: from initial neuroinvasion to HIV-associated neurocognitive disorder 
(HAND). Curr. HIV/AIDS Rep. 12, 16-24. doi: 10.1007/s11904-0140255-3

Zhang, D., Snyder, A. Z., Shimony, J. S., Fox, M. D., and Raichle, M. E. (2010). Noninvasive functional and structural connectivity mapping of the human thalamocortical system. Cereb. Cortex 20, 1187-1194. doi: 10.1093/cercor/bhp182

Zhu, T., Zhong, J., Hu, R., Tivarus, M., Ekholm, S., Harezlak, J., et al. (2013). Patterns of white matter injury in HIV infection after partial immune reconstitution: a DTI tract-based spatial statistics study. J. Neurovirol. 19, 10-23. doi: 10.1007/s13365-012-0135-9
Conflict of Interest Statement: The author declares that the research was conducted in the absence of any commercial or financial relationships that could be construed as a potential conflict of interest.

Copyright $\odot 2018$ Zahr. This is an open-access article distributed under the terms of the Creative Commons Attribution License (CC BY). The use, distribution or reproduction in other forums is permitted, provided the original author(s) and the copyright owner are credited and that the original publication in this journal is cited, in accordance with accepted academic practice. No use, distribution or reproduction is permitted which does not comply with these terms. 